\title{
MASTER
}

\section{Particle Size Analysis of hMX}

A. A. Duncan

DEVELOPMENT DIVISION

\section{OCTOBER 27,1972}

\section{NOTICE $\backslash$ MN ONLY.}

PORTIONS OF THIS REPORT ARE ILLEGIBLE. It has been reproduced from the best available copy to permit the broadest possible availability.

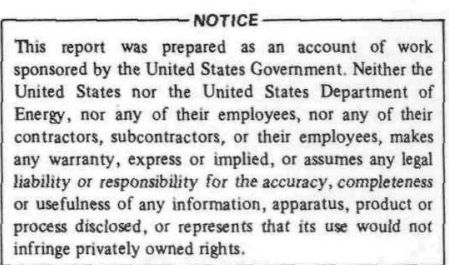

For

Hercules Incorporated

Magna, Utah

DISTRIBUTICN OE TISS DOCUMENT IS U A ATTED 


\section{DISCLAIMER}

This report was prepared as an account of work sponsored by an agency of the United States Government. Neither the United States Government nor any agency Thereof, nor any of their employees, makes any warranty, express or implied, or assumes any legal liability or responsibility for the accuracy, completeness, or usefulness of any information, apparatus, product, or process disclosed, or represents that its use would not infringe privately owned rights. Reference herein to any specific commercial product, process, or service by trade name, trademark, manufacturer, or otherwise does not necessarily constitute or imply its endorsement, recommendation, or favoring by the United States Government or any agency thereof. The views and opinions of authors expressed herein do not necessarily state or reflect those of the United States Government or any agency thereof. 


\section{DISCLAIMER}

Portions of this document may be illegible in electronic image products. Images are produced from the best available original document. 


\title{
Particle Size Analysis of hMX
}

\author{
A. A. Duncan \\ DEVELOPMENT DIVISION
}

October 27, 1972

P.O. No. 085I-03-180

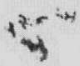




\title{
Particle Size Analysis of H'R For Hercules Incorporated
}

\author{
INTRODUCT ION
}

Particle size distrikution ( $\pi$ ) of three batches of Hercules-supplied HMX have been analyzed by the Pantex Development Division. II's were determined by the specified sieve analysis having a nest range of 180 through $10 \mu$. These sieves were used to comply with Hercules requests; they are also those customarily used fcr HMX qualification. Five analyses for each batch were performed on the material $>10 \mu$ and duplicates analysis for the < $10 \mu$ material.

On August 22, 1972 Rcibert Sthnettler visited our laboratory to discuss particle size analysis. He okserved sieve analysis performed on the Pantex automatic sieving apparatus. Written procedures involving sieving HMX as well as a complete set of blueprints of the sieving apparatus were given to him at that time. Later, upon the request of F. Levitt, a complete set of Sepia prints of the sieving apparatus was mailec to Hercules.

The effects of ultrasonic vibration on HMX particle size are of interest to Hercules (having been discussed by telephone with Sthnettler) and a study on that is included in this report. Specific procedures used in the sieving of HMX as well as a discussion of sieve analysis and the Pantex sieving apparatus are also included.

Particle Distribution of Hercules Supplied HMX

The sieve analysis consisting of 5 runs for each of three batches of HMX has been completed by Pantex for Hercules Incorporated, Bacchus Works Plant, Magne, Utah. The analysis simulates Holston's analysis (which in turn was a consequence of our early work on small sieves). Isobutyl acetate was used as an elutant to separate HMX through a nest consisting of sieve sizes 180, 150, 130, 100 and increments of $10 \mu$ down to $10 \mu$. Duplicate analysis below $10 \mu$ was done in increments of 8,6 , 4 , and $2 \mu$.

Batch identification were as follows:

1. 930-6 Sample $16 \mathrm{H} 6 \mathrm{~F}$ 62-57

2. $961-5 \mathrm{E}$

3. $\mathrm{L} / \mathrm{N} 148-61$

Sieve analysis show batches $961-5 \mathrm{E}$ and $930-6$ to be similar in distribution; each retained approximately the same amount of material on each sieve. Batch 961-5E had an arithmetic mean particle size of $11.01 \mu$, while batch 930-6 arithmetic mean was $16.29 \mu$. Batch $L / N$ 148-61 was evenly distributed: the weight percentage retained for the various sieves were nearly equal. The major modes at $100 \mu$ and $60 \mu$ were $\sim 12 \%$ while the other sieves were $\sim 5 \%$. The arithmetic mean particle size for $\mathrm{L} / \mathrm{N}$ 148-61 was $69.59 \mu$. Distributions for each batch are shown in condensed forms in Tables I, II; and III; detailed computer printout and plots are in enclosures I, II, and III (plots for each respective batch are at the end of its appropriate enclosure). 
I's were based on the weight of retained by each sieve. Particle size was denoted as that of the sieve; calibration, by microscopy, of each sieve's average opening was within $\pm .5 \mu$.

Weight percentage retained is calculated by the weight retained divided by the total weight retained $\times$ 100. Tctal weight retained is used instead of starting sample weight because samples were hot dried before sieving, and sample loss is not linear with respect to size. For each duplicate in enclosures I, II, and III, a combined analysis is calculated. This is done by adding the weight retained in analyses 1 and 2 for each sieve divided by combined total retained for both analyses $x$ 100. This is done to minimize sampling error, which would be more effective than averaging the weight setained. Tables I, II and III have combined analyses for the total retained for the 5 analyses on each sieve divided by total retained for all 5 analyses $\times 100$. (Do not confuse an average of the weight of retained with the combined analysis. Mean weight: of retained are shown in column 10 of each table.) Standard deviation in weight $\%$ retalned for each sieve $>10 \mu$ were all $<0.8 \%$ and average 0.28 . For any analysis having a standard deviation < 18 the procedure may be sald to be very reproducible. Accuracy must be achieved by proper washing, calibration of sieves and appropriate particle shape.

Standard deviation $=s=\sqrt{\frac{\sum_{i=1}^{N}\left(x_{i}-\bar{x}\right)^{2}}{N-1}}$

Variance $=s^{2}=\frac{\sum_{j=1}^{N}\left(x_{i}-\ddot{x}\right)^{2}}{N-1}$

Arlthmetic mean for weight retained and is not be confused with arithmetic mean particle size calculated in the detail print outs in enclosures I, II, and III because the latter is based on sieve size and not weight retained.

Arithmetic mean $=\bar{x}=\sum_{\frac{i=1}{N} x_{i}}^{N}$

Arithmetic mean based on particle size between two sieves.

$\left.\bar{x}_{\alpha}=\sum_{i=1}^{N} \frac{\left[\left(\frac{x_{1}+x_{2}}{2}\right)\right.}{w} w_{i}\right]$

with $x_{1}$ being upper sieve size and

$x_{2}$ bottom sieve size of two adfacent sleves

$w_{i}$ welght retained between sieves $x_{1}$ and. $x_{2}$

$w$ total weight retained by sieve nest.

Geometric mean based on geometric mean particle size betweer two sieves.

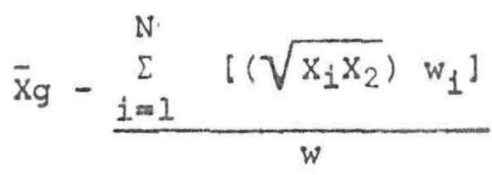

The differences are significant, thus emphasizing the need for stating clearly how particle size average of screened material are derived. 
TABLE I. HERCULES HMX 930-6 Sample 1 6H6F 62-57

Weight \& Retained

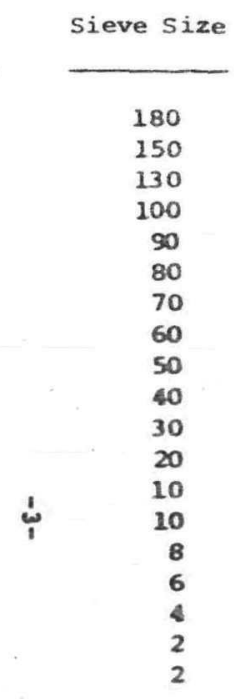

\begin{tabular}{|c|c|}
\hline $\begin{array}{c}\text { Analys is } \\
1 \\
\end{array}$ & $\begin{array}{c}\text { Analys is } \\
2 \\
\end{array}$ \\
\hline .27 & .57 \\
\hline .25 & .58 \\
\hline .25 & .53 \\
\hline .35 & .50 \\
\hline .65 & .78 \\
\hline .60 & .90 \\
\hline .65 & .93 \\
\hline 1.35 & 1.55 \\
\hline 2.10 & 2.14 \\
\hline 3.94 & 3.24 \\
\hline 6.94 & 7.30 \\
\hline 6.60 & 6.64 \\
\hline 12.82 & 12.93 \\
\hline 63.22 & 61.46 \\
\hline 7.02 & 7.41 \\
\hline 37.95 & 34.62 \\
\hline 6.05 & 9.02 \\
\hline 11.60 & 10.19 \\
\hline .59 & .22 \\
\hline
\end{tabular}

\begin{tabular}{|c|c|c|c|}
\hline $\begin{array}{c}\text { Analysis } \\
3 \\
\end{array}$ & $\begin{array}{c}\text { Analys is } \\
\quad 4 \\
\end{array}$ & $\begin{array}{c}\text { Analysis } \\
5 \\
\end{array}$ & $\begin{array}{l}\text { Combined } \\
\text { Analysis }\end{array}$ \\
\hline .56 & .48 & .50 & .42 \\
\hline .61 & .45 & .60 & .45 \\
\hline .72 & .57 & .58 & .46 \\
\hline .74 & .59 & .63 & .52 \\
\hline .87 & .73 & .91 & .76 \\
\hline .81 & .66 & .83 & .73 \\
\hline .91 & 1.06 & .95 & .85 \\
\hline 1.68 & 1.39 & 1.51 & 1.47 \\
\hline 2.54 & 2.19 & 2.23 & 2.21 \\
\hline 4.18 & 4.10 & 3.42 & 3.81 \\
\hline 7.00 & 6.67 & 7.46 & 7.05 \\
\hline 6.40 & 6.71 & 6.65 & 6.60 \\
\hline 12.29 & 13.04 & 12.24 & $12.70^{\circ}$ \\
\hline 60.70 & 61.40 & 61.49 & 61.97 \\
\hline & & & 7.15 \\
\hline & & & 36.92 \\
\hline & & & 6.97 \\
\hline & & & 11.16 \\
\hline & & & .48 \\
\hline
\end{tabular}

\& Coarser

Than Sieve

Size.

.42
.87
1.33
1.86
2.61
3.35
4.20
5.66
7.87
11.68
18.73
25.33
38.03
100.00

c Average

(Microns)

Gecoetric Average

.16
.48
Finer

Than Sieve

Size

99.58

98.13

98.67

98.14

97.39

96.65

95.80

94.34

92.13

88.32

81.27

74.67

61.97

.00
Arithmetic

mean

Variance

0.0101

0.0187

0.0233

0.0172

0.0088

0.0125

0.0183

0.0139

$\begin{array}{ll}2.240 & 0.0244 \\ 3.776 & 0.1418\end{array}$

$7.074 \quad 0.0773$

$6.600 \quad 0.0112$

1600.11

12.6640 .1112

61.6540 .6983

$\begin{array}{rr}7.215 & 0.0380 \\ 36.285 & 2.7722\end{array}$

$\begin{array}{rr}36.285 & 2.7722 \\ 7.535 & 2.2052\end{array}$

\begin{tabular}{l}
$7.535 \quad 2.2052$ \\
\hline
\end{tabular}

$10.895 \quad 0.4970$

$.405 \quad 0.0342$

16.29

16.07
Standard

Deviation

0.1005

1367

.1528

0.1311

0.0939

0.1119

0.1354

.1563

0.278

0.1060

0.3335

1950

1.6650

1.4850

0.7050

0.1850 
TABIE II. HERCULES HMX 961-5E

Weight \& Retained

\begin{tabular}{c}
$\begin{array}{r}\text { Sieve Size } \\
\text { (microns) }\end{array}$ \\
\hline 180 \\
150 \\
130 \\
100 \\
90. \\
80 \\
70 \\
60 \\
50 \\
40 \\
30 \\
20 \\
10 \\
10 \\
8 \\
6 \\
4 \\
1 \\
2 \\
\\
6
\end{tabular}

\begin{tabular}{|c|c|}
\hline $\begin{array}{c}\text { Analys is } \\
1\end{array}$ & $\begin{array}{c}\text { Analysis } \\
2\end{array}$ \\
\hline .36 & .26 \\
\hline .35 & .36 \\
\hline .41 & .40 \\
\hline .37 & .54 \\
\hline .57 & 1.12 \\
\hline .54 & .70 \\
\hline .50 & .99 \\
\hline .70 & .96 \\
\hline .66 & .82 \\
\hline .91 & 1.46 \\
\hline 2.07 & 2.13 \\
\hline 3.31 & 3.60 \\
\hline 14.54 & 13.27 \\
\hline 74.72 & 73.40 \\
\hline 9.06 & 1.01 \\
\hline 38.45 & 47.65 \\
\hline 13.01 & 4.27 \\
\hline 13.69 & 14.61 \\
\hline
\end{tabular}

\begin{tabular}{|c|c|c|}
\hline $\begin{array}{c}\text { Analys is } \\
3 \\
\end{array}$ & $\begin{array}{c}\text { Analysis } \\
4\end{array}$ & $\begin{array}{c}\text { Aralysis } \\
5 \\
\end{array}$ \\
\hline .47 & .41 & .24 \\
\hline .42 & .48 & .28 \\
\hline .54 & .52 & .38 \\
\hline .55 & .60 & .42 \\
\hline .71 & .82 & .72 \\
\hline .68 & .69 & .53 \\
\hline .77 & .62 & .60 \\
\hline 1.11 & 1.01 & .55 \\
\hline .98 & .97 & .76 \\
\hline 1.23 & 1.02 & .92 \\
\hline 2.27 & 2.16 & 1.90 \\
\hline 3.49 & 3.64 & 3.45 \\
\hline 14.09 & 14.52 & 13.72 \\
\hline 72.69 & 72.54 & 75.54 \\
\hline
\end{tabular}

\begin{tabular}{r} 
Combined \\
Analysis \\
\hline .35 \\
.28 \\
.45 \\
.48 \\
.77 \\
.62 \\
.68 \\
.85 \\
.82 \\
1.09 \\
2.10 \\
3.48 \\
14.08 \\
73.87
\end{tabular}

- Coarser Than Sieve Size

.35
.72
1.17

.72
1.17
1.65

1.65
2.42

3.04

3.71

4.56

5.38 6.47

8.57

12.04

26.13
100.00

Piner

Than Sieve

Size

99.65

99.28

98.83

98.35

96.96

96.29

95.44

94.62

93.53

91.43

87.96

73.87
0.00

Arithetic Average (microns)

Gecmetric Averagee.

Weight \& Retained

\begin{tabular}{|c|c|c|}
\hline $\begin{array}{c}\text { ithmetic } \\
\text { Mean }\end{array}$ & Variance & $\begin{array}{l}\text { Standard } \\
\text { Deviation }\end{array}$ \\
\hline .348 & 0.0077 & 0.0875 \\
\hline .378 & 0.0046 & 0.0576 \\
\hline .450 & 0.0044 & 0.0663 \\
\hline .496 & 0.0075 & 0.0864 \\
\hline .788 & 0.0339 & 0.1841 \\
\hline .628 & 0.0058 & 0.0763 \\
\hline .696 & 0.0291 & 0.1705 \\
\hline .866 & 0.0433 & 0.2081 \\
\hline .838 & 0.0151 & 0.1230 \\
\hline 1.108 & 0.0442 & 0.2103 \\
\hline 2.106 & 0.0148 & 0.1218 \\
\hline 3.498 & 0.0137 & 0.1169 \\
\hline 14.028 & 0.2355 & 0.4853 \\
\hline 73.778 & 1.3703 & 1.1706 \\
\hline 7.535 & 2.3256 & 1.5250 \\
\hline 43.05 & 21.600 & 4.6000 \\
\hline 8.640 & 19.0967 & 4.3700 \\
\hline 14.150 & .2116 & .4600 \\
\hline .68 & 0.0289 & 0.1700 \\
\hline
\end{tabular}

11.01 
TABLE III. HERCULES HMX L/N 148-61

Weight \& Retained

Weight \& Retained

\begin{tabular}{|c|c|c|c|c|c|c|c|c|}
\hline $\begin{array}{r}\text { Sieve Size } \\
\text { (microns) }\end{array}$ & $\begin{array}{c}\text { Analys is } \\
1\end{array}$ & $\begin{array}{c}\text { Analysis } \\
2 \\
\end{array}$ & $\begin{array}{c}\text { Analysis } \\
3 \\
\end{array}$ & $\begin{array}{c}\text { Analysis } \\
4 \\
\end{array}$ & $\begin{array}{c}\text { Analys is } \\
5 \\
\end{array}$ & $\begin{array}{l}\text { Conbined } \\
\text { Analysis }\end{array}$ & $\begin{array}{c}\text { Than Sieve } \\
\text { Size } \\
\end{array}$ & $\begin{array}{c}\text { of Finer } \\
\text { Than Sieve } \\
\text { Size }\end{array}$ \\
\hline 180 & 2.44 & 1.55 & 1.89 & 2.27 & 1.95 & 2.04 & 2.04 & 97.96 \\
\hline 150 & 3.94 & 4.60 & 4.15 & 4.41 & 4.63 & 4.34 & 6.38 & 93.62 \\
\hline 130 & 3.87 & 4.11 & 4.27 & 3.95 & 4.12 & 4.05 & 10.43 & 89.56 \\
\hline 100 & 12.04 & 12.05 & 12.02 & 12.24 & 12.23 & 12.12 & 22.56 & 77.44 \\
\hline 90 & 9.77 & 9.42 & 9.86 & 9.79 & 9.83 & 9.74 & 32.30 & 67.70 \\
\hline 80 & 6.90 & 6.47 & 5.96 & 6.02 & 6.97 & 6.44 & 38.74 & 61.26 \\
\hline 70 & 6.28 & 7.19 & 7.37 & 7.01 & 6.46 & 6.86 & 45.60 & 54.396 \\
\hline 60 & 12.11 & 11.36 & 11.86 & 11.46 & 11.65 & 11.68 & 57.29 & 42.71 \\
\hline 50 & 6.03 & 5.96 & 6.08 & 6.75 & 6.39 & 6.27 & 63.55 & 36.45 \\
\hline 40 & 9.79 & 8.94 & 8.71 & 9.05 & 8.95 & 9.09 & 72.65 & 27.35 \\
\hline 30 & 6.10 & 6.54 & 6.68 & 6.39 & 6.68 & 6.47 & 79.11 & 20.89 \\
\hline 20 & 3.59 & 4.12 & 4.30 & 3.56 & 3.75 & 3.84 & 82.95 & 17.05 \\
\hline 10 & 4.02 & 4.24 & 4.17 & 3.96 & 4.10 & 4.09 & 87.04 & 12.96 \\
\hline 10 & 13.12 & 13.46 & 12.69 & 13.14 & 12.28 & 12.96 & 100.00 & 0.0060 \\
\hline 8 & 1.46 & & & & 1.22 & & & \\
\hline 6 & 3.41 & & & & 5.16 & & & \\
\hline 4 & 2.46 & & & & 1.98 & & & \\
\hline 2 & 5.68 & & & & 3.74 & & & \\
\hline 2 & 0.11 & & & & .18 & & & \\
\hline
\end{tabular}

Arithmetic Average Gecmetric Average

\begin{tabular}{rll}
$\begin{array}{c}\text { Arithmetic } \\
\text { Mean }\end{array}$ & & \\
\cline { 1 - 1 } 2.020 & & 0.0963 \\
4.346 & & 0.0705 \\
4.064 & & 0.0197 \\
12.116 & & 0.0095 \\
9.734 & & 0.0256 \\
6.464 & & 0.1795 \\
6.862 & & 0.1776 \\
11.688 & & 0.0737 \\
6.242 & & 0.0861 \\
9.088 & & 0.1356 \\
6.478 & & 0.0472 \\
3.864 & & .0872 \\
4.098 & & 0.0101 \\
12.938 & & 0.1682 \\
1.340 & & 0.0144 \\
4.285 & & 0.7656 \\
2.220 & & 0.0576 \\
4.710 & & 0.9409 \\
.145 & 0.0012
\end{tabular}

Standard norriation

0.3104

0.2655

0.1402

0.0977

0.1601

$\begin{array}{llll}.26 & 6.464 & 0.1795 & 0.4236\end{array}$

396

4.45

.89

2.96

(a) 
Steve analysis has been widely used in measuring particle size distribution ( $\pi$ ) and is used in this case because of the ease with which a relatively large sample can be characterized.

HNX is ideal for sieving in that size and shape are appropriate. Many explosives have particle shapes that do not allow proper separation but HMX is slightly elliptical and of ten ranges from 350 to $10 \mu$ in size. HMX II's are derived by sieving the powder through a nest of sieves and from the weight retained, weight percent is calculated. Quite often additional information is desired and thus study can be made in which sieve intervals can be used to better estimate distribution means and specific surface area. In order to gain a valid estimate of particle distributions, the principles of sieve analysis should be understood, e.g., effects of particle shape, orientation, dynamic locking, sieve loading, etc., on particle retention. Some prinsiples of sieve analysis are discussed herein.

\section{DISCJSSION}

Sieve analysis has been considered by many analysts as the most rapid and easiest method to obtain a $\pi$. Basically, sieve analysis is the flacing of a standard in the path of a moving particle which acts as a means of resistance by which particles are measured through retainment or passage. Ideally this means that particles greater than the sieve aperture are retainec and those passing must be smaller than the aperture; thus, the ultimate goal is to segregate particles above or below a given aperture. The simplicity of these concepts gives the general idea that sieve analysis is simple, but to achieve accuracy and precision it can become extremely complicated.

Sieve analysis is usually performed by using a series of sieves having different size apertures, one upon the other, with the aperture size increasing ujward in the vertical direction. The sample is placed on the upper sieve, which has the largest opening. The entire stack of sieves (nest) is then shaken and/or washed with an elutant until the sample distributes itself on the individual sieves. Theoretically, it appears that each particle has found its remaining sieve; however, this may not be true enough unless the inherent problems of sieving are eliminated. Inherent problems of sieving are as follows:

\section{A. Electrostatic Adherence}

Most powders generate static electricity when being sifted, thus fine particles adhere to the screen or each other, causing them to be deposited on screens that have apertures larger than their dimensions. This results in a shift in the distribution toward the coarser size: To eliminate this problem wet sieving is generally preferred and should be used with any powder having particle $<20 \mu$. In wet sieving, high density moderate vapor pressure liquids are desired because of their flow properties. However, any liquid can be used that does not dissolve the particles to be sieved or react with the sieve's construction. 


\section{B. Particle Agglomeration}

Agglomeration, due to weak bonding, must be eliminated before an accurate sieve analysis can be made. Wet sieving is preferred in that the agglomerated particles may be dispersed in an elutant by shaking or ultrasonic vibration before sieving. For powders difficult to disperse, wetting agents may be added to the elutant to assure adequate surface wetting.

C. Particle Abrasion

For brittle particles it has been found that repeated collision with the sieve surface or other particles tend to fracture particles causing a reduction in particle size. When excessive sieve time is required to separate particles, wet sieving is generally used to reduce impact velocity. If ultrasonic vibration is used to separate particle agglomerates a maximum duration must be determined, because ultrasonic vibration can fracture and abrade particles.

D. Sieve Abrasion

When sieving particles which are harder than the metals of the sieve construction, abrasion occurs which will increase the sieve's apertures. In sieving these powders a minimum sieving tine should be used and fyequent calibration of the sieves made. Extreme care should be used when washing and cleaning sieves in that the fragile construction of the mesh can be damaged, resulting in an alteration of the sleve's openings.

E. Sieve Apertures

For proper sieve analysis the openings of an individual sieve should be as accurate and alike as possible, because off-size apertures, as is apparent, will pass or retain particles less or greater than the nominal sieve size causing improper segregation of these particles. Thus, distributions generated from these sieves do not relate to the actual powder distribution. Wire woven sieves have apertures that vary as much as 15 r (and with continued use the variance in aperture size increases). Electroformed sieves are far superior to wire woven sieves in that the variance in sieve apertures is generally quite small. In the larger aperture electroformed sieves the variance is $\pm 2 \mu$, in the smaller sieves (<;20i), 'it is $\pm 1 \mu$. Electroformed sleves have greatly improved the accuracy of determing powder distributions.

\section{F. Nest Distributions}

An adequate number of sieves must be used to determine the powder distribution and mode intervals. Many powders have boen found which exist with more than one mode. Thus initial testing should be done with as many sieves as possible to find the major modes and then sieves not pertinent to bracket these modes may be eliminated. Bracketing sieves are important in reducing sleve load for major sieves, e.g., to prevent overloading. 


\section{G. Inclined Screening}

The effective opening of sieves can be reduced by placing the sieve in an inclined position. Pitch on an inclined screen reduces the actual opening to a smaller effective opening due to the angle at which particles carried by gravity will strike the aperture. Inclining the screen should be avoided when accurate sieving analysis are to be made.

H. Dynamic Locking

Dynamic locking is due to the motion of the screen. In sieving powders, particles are normally in motion about the screen surface. If not, particle stoppage can occur regardless of particle size, after the initial motion of the particles to the sieve surface, unless an aperture is found. Thus the sieves are normally shaken, oscillated, thumped, etc., to place the particles in motion about the sieve to eliminate clogging. Sieve movement which is necessary has also been found to be critical as to speed and direction. Speed is important in that a rapid horizontally moving sieve has a tendency to present to a falling particle a grid instead of an opening. With slow horizontal movement a particle has a greater probability of finding a sieve aperture before the end of the operation. When a particle becomes stationary on the sieve surface (occasionally due to frictional forces) this particle tends to ride the surface. When a particle is frictionally bound, the particle and sieve proceed in the same direction at the same speed. Therefore, the screen must be moved at a speed so that frictional binding is overcome. Direction now becomes important and is basically of two kinds: (1) horizontal, which means the sieve moves perpendicular to the particle's normal gravitation direction, (2) vertical movement, which is intended to agitate and mix the particles by tossing them above the sieve. Fahrenwald and stockdale (1) carried out an intensive study of the above sieve motions and found that machines using horizontal movement were not as efficient as those using vertical movement.

I. Sieve Blinding Due to Overloading

Overloading of sieves leads to inaccurate results because of improper segregation of particles due to aperture blockage by oversize particles. During sieving two major passages occur: (1) fines easily pass the aperture, and (2) some particles just pass the sieve aperture. The fines pass quite rapidly, unless overloading occurs; and thus the bulk of the sieving time is related to the passage of those particles which just pass a sieve aperature.

(1) Effects of Sieve Motions on Screening Efficiency, Buredu of Mines, Serial 
For a near-mesh particle close to the aperture sieve, orientation to the aperture is critical for passage and, it must usually be continually lifted from the sieve surface and presented again to another portion of the sieve surface. Because a powder layer on a sieve is several particles thick, then the probability of a near-mesh particle finding an unoccupied aperture is quite small. Thus, mixing and presenting the particles to the sieve would be an endless process in order to get every particle to pass those sieves larger than the particle's dimensions. Prolongation of sieving time does improve the probability that a near-mesh particle finds an aperture for passage; however, if overloading occurs the probability decreases again, because of particles being trapped between other particles. Overloading therefore is not related to gross amount added to a sieve, but to the proportion that does not pass through the sieve readily. The sample size should be set by this factor. It should also be kept in mind that prolongation for segregation in sieving time may not improve particle passage as much as reduction in sample size. The ASTM method of sample size restricts the amount of material retained by a specific sieve to be less than a certain weight per square inch of sieving surface. This weight varies for specific materials and is a function of density, which essentially restricts the number of particles per sieve to avoid aperture masking.

J. Sieving Time

Sieving time has been generally regulated by one of three criteria.

1. By standard time of sieving. This method has been adopted by the British Bureau of Standards \#12,1931. When using this method one normally predetermines time required for adequate separation by observing retention after various times by microscopy.

2. By stating that sieving must be continued until the weight of powder passing the sieve per minute is less than a certain percent of the total weight of the sample taken (American Standard 1926D).

3. By stating that sieving must be continued until the weight of material passing the sieve per run is less than a certain proportion of the weight retained on that sieve.

Method 3 is the better method, although in wet sieving it is more complicated. However, it does set limits on the retaining material which takes into account near-mesh particles.

These three methods of determining end points are widely used and any of them would give reproducibility, which is important. Most analysts state that complete separation is not possible; therefore set sieving time at 
a point where most of the readily passable particles have passed and where the passing rate of near-mesh size is small. To be safe a near-mesh particle count should be made to determine that failure to pass is not due to overloading. A general procedure to follow on new material analysis is to use one of the old test procedures and see where the modes occur. Check the retained powder on the major mode sieves by microscopy to see how many undersize particles have been retained. Then determine if the retainment of fines is due to insufficient sieving time or overloading. Large numbers of readily passable particles means overloading and liarge numbers of near-mesh particles is usually due to insufficient duration. From this test sample nest size and sieving time can usually be determined.

\section{K. Aperture Shape}

Sieves of several kinds have been used, e.g., those having round, rectangular slits, or square openings. Square openings are generajlit favored because there is less orientation effect. Square openings reduce the corridors found in slitted screens. (In a square of 2011 the corridor along the diagonal will allow up to $28 \mu$ to pass if thej.r $\mathrm{L} / \mathrm{W}$ or $\mathrm{W} / \mathrm{H}$ ratio is favorable; the effect with slits is obvious, ) Round openings were introduced to eliminate corridor effects. For rectangular and cubic particles round openings do not adequately represent the restricting particle dimensions in that a round opening requires a diameter that equals the diagonals and not side dimensions. Round openings are best suited for spherical particles, but square openings relate to spherical diameter anyway. The additional opening area afforded by square openings speeds sphere passage, e.g., in wet sieving by increasing elutant flow.

\section{Particle Retainment}

If we consider a single square aperture perpendicular to the approach of a particle then the factors involved in retention have to do with all the dimensions of the particles. Retainment may be due to each of its dimensions separately or in combination, forming a diagonal. For a single rectangular particle many combinations can cause retainment; the parameter that does so is sometimes called the approach dimension.

Approach dimensions vary according to the shape of the particles; spheres have but one dimension(obviously the diameter of the sphere) while cubes have one side or diagonals that can cause stoppage.

When a particle has dimensions such that length $>$ width > depth then several approach dimensions must be taken into account. For example, particles having length 858 of the corridor length an $\mathrm{L} / \mathrm{W}$ ratio of $\sim 5.8$ is required for corridor passage. In order. for a particle having length 998 of the corridor length to pass a $\mathrm{L} / \mathrm{W}$ ratio of 39.0 would be necessary. Thus it can be seen that extremely high L/W ratios are required for corridor passage and that orientation is critical.

Irregularly shaped particles gain more corridor passage, as particle dimensions become more varied; the powder analysis likewise becomes more varied. 
The sieving of irregularly shaped particles tend to be more governed by the laws of chance and reproducibility of such distributions are often poor.

M. Angle of Approach

Mesh thickness does not appear important in particle passage, except that elutant flow may be decreased by the thicker mesh and should be avoided if possible. If the mesh thickness is not too great high angles of approach (angle between the direction of fall and the vertical) do not increase flow impedance much.

In order to study dimension effects on sieve analysis, a sample of HMX was sieved in duplicates and from the powder retained on each sieve; samples were removed for microscopy analysis. By measuring particle dimensions for the various particles found retained on the sieves, segregation according to approach dimension were studied. In addition to the material retained on the sieves, upon drying a small percentage of particles are found to fall through the sieves; the particles that passed thus upon elutant drying were also measured.

In this study the primary dimensions analyzed were length and width. Fran Table IV, the effectiveness of the sieving time and sample size can be seen: only $0.6 \%$ of the particles retained on each sieve had both width and length less than the retaining aperature.

When sieving analysis is done wet, each sieve must be dried before the weight of material retained can be determined. After drying, particles have been found beneath the sieves. From all indications the majority of the particles passing were near-mesh size and only $4.3 \%$ had both dimensions less than the passing aperture.

\section{COMMENTS AND CONCLUSIONS}

Sieve analysis, an extremely useful method in describing $\pi$ for some kinds of particles should be performed in a manner which avoids the inherent problems involved in sieving. Wet sieving has been found by our laboratory to be far more reproducible when sieving particles below 2000 in size. Wet sieving reduces particle attrition due to impact upon the sieve surface and with other particles. Deagglomeration by use of ultrasonic vibration while the sample is in a liquid is very helpful in that the sample is placed on the sieves while wet so that agglomeration does not recur. Ultrasonic vibration does change particle size when done for an excessive length of time, therefore a maximum time must be determined for each specific material to be sieved. Elutants are frequently used as a solvent for binders in formulated materials and should be selected on the basis of the best solvent for binders 
Table IV. HMX Analysis

$\underline{\text { Sieve Cuts }}$

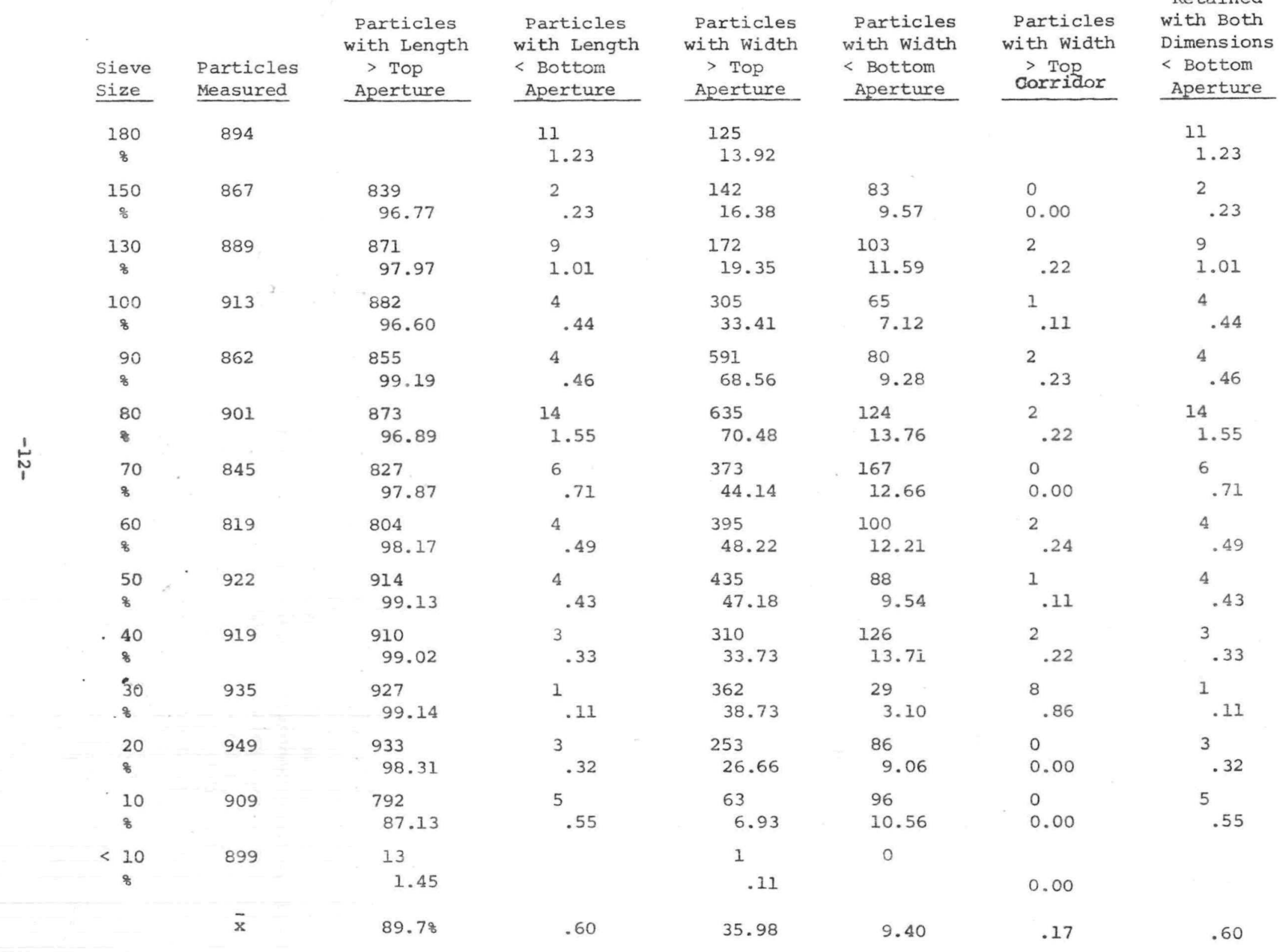


Table v.

Particles Passed After Sieving

\begin{tabular}{|c|c|c|c|c|c|c|c|c|}
\hline $\begin{array}{l}\text { Sieve } \\
\text { Size } \\
\end{array}$ & $\begin{array}{c}\text { Particles } \\
\text { Passed } \\
\end{array}$ & $\begin{array}{l}\text { Having Length } \\
>\text { Passing } \\
\text { Aperture } \\
\end{array}$ & $\begin{array}{c}\text { Having Length } \\
>\text { Passing } \\
\text { Corridor } \\
\end{array}$ & $\begin{array}{c}\text { Particles } \\
\text { Having Width } \\
>\text { Passing } \\
\text { Aperture } \\
\end{array}$ & $\begin{array}{l}\text { Particles } \\
\text { with Width } \\
<\text { Passing } \\
\text { Aperture } \\
\end{array}$ & $\begin{array}{l}\text { Particles } \\
\text { with Width } \\
>\text { Passing } \\
\text { Corridor } \\
\end{array}$ & $\begin{array}{r}\text { Particles } \\
\text { with Both } \\
\text { Dimensions } \\
<\text { Passing } \\
\text { Coeloor } \\
\end{array}$ & $\begin{array}{l}\text { Particles } \\
\text { Width } \\
<\text { Passing } \\
\text { Corridor } \\
\end{array}$ \\
\hline $\begin{array}{c}180 \\
8\end{array}$ & 85 & $\begin{array}{l}85 \\
100.00\end{array}$ & $\begin{array}{l}74 \\
87.06\end{array}$ & $\begin{array}{l}70 \\
82.35\end{array}$ & $\begin{array}{l}15 \\
17.65\end{array}$ & $\begin{array}{l}45 \\
52.94\end{array}$ & $\begin{array}{l}0 \\
0.00\end{array}$ & $\begin{array}{l}40 \\
47.06\end{array}$ \\
\hline $\begin{array}{c}150 \\
\text { if }\end{array}$ & 58 & $\begin{array}{l}52 \\
89.66\end{array}$ & $\begin{array}{l}47 \\
81.03\end{array}$ & $\begin{array}{l}45 \\
77.59\end{array}$ & $\begin{array}{l}13 \\
22.41\end{array}$ & $\begin{array}{l}8 \\
13.79\end{array}$ & $\begin{array}{c}6 \\
10.34\end{array}$ & $\begin{array}{l}50 \\
86.21\end{array}$ \\
\hline $\begin{array}{c}130 \\
8\end{array}$ & 174 & $\begin{array}{l}166 \\
95.40\end{array}$ & $\begin{array}{l}141 \\
81.03\end{array}$ & $\begin{array}{l}136 \\
78.16\end{array}$ & $\begin{array}{l}38 \\
21.84\end{array}$ & $\begin{array}{l}3 \\
1.72\end{array}$ & $\begin{array}{l}8 \\
4.60\end{array}$ & $\begin{array}{l}171 \\
98.28\end{array}$ \\
\hline $\begin{array}{c}100 \\
8\end{array}$ & 213 & $\begin{array}{l}205 \\
96.24\end{array}$ & $\begin{array}{l}149 \\
69.95\end{array}$ & $\begin{array}{l}136 \\
63.85\end{array}$ & $\begin{array}{l}77 \\
36.15\end{array}$ & $\begin{array}{l}6 \\
2.82\end{array}$ & $\begin{array}{l}8 \\
3.76\end{array}$ & $\begin{array}{l}207 \\
97.18\end{array}$ \\
\hline $\begin{array}{l}90 \\
8\end{array}$ & 183 & $\begin{array}{l}183 \\
100.00\end{array}$ & $\begin{array}{l}31 \\
16.94\end{array}$ & $\begin{array}{l}151 \\
82.51\end{array}$ & $\begin{array}{l}32 \\
17.49\end{array}$ & $\begin{array}{l}8 \\
4.37\end{array}$ & $\begin{array}{l}0 \\
0.00\end{array}$ & $\begin{array}{l}175 \\
95.63\end{array}$ \\
\hline $\begin{array}{l}80 \\
8\end{array}$ & 356 & $\begin{array}{l}339 \\
95.22\end{array}$ & $\begin{array}{l}226 \\
63.48\end{array}$ & $\begin{array}{l}171 \\
48.03\end{array}$ & $\begin{array}{l}185 \\
51.97\end{array}$ & $\begin{array}{l}5 \\
1.40\end{array}$ & $\begin{array}{r}17 \\
4.78\end{array}$ & $\begin{array}{l}351 \\
98.60\end{array}$ \\
\hline $\begin{array}{l}70 \\
8\end{array}$ & 489 & $\begin{array}{l}449 \\
91.82\end{array}$ & $\begin{array}{l}256 \\
52.35\end{array}$ & $\begin{array}{l}163 \\
33.33\end{array}$ & $\begin{array}{l}326 \\
66.67\end{array}$ & $\begin{array}{l}0 \\
0.00\end{array}$ & $\begin{array}{l}40 \\
8.18\end{array}$ & $\begin{array}{l}489 \\
100.00\end{array}$ \\
\hline $\begin{array}{l}60 \\
8\end{array}$ & 236 & $\begin{array}{l}227 \\
96.19\end{array}$ & $\begin{array}{l}127 \\
53.81\end{array}$ & $\begin{array}{l}88 \\
37.29\end{array}$ & $\begin{array}{l}148 \\
62.71\end{array}$ & ${ }^{1} .42$ & $\begin{array}{l}9 \\
3.81\end{array}$ & $\begin{array}{l}235 \\
99.58\end{array}$ \\
\hline $\begin{array}{l}50 \\
\%\end{array}$ & 107 . & $\begin{array}{l}99 \\
92.52\end{array}$ & $\begin{array}{l}69 \\
64.49\end{array}$ & $\begin{array}{l}61 \\
57.01\end{array}$ & $\begin{array}{l}46 \\
42.99\end{array}$ & ${ }^{1} .93$ & $\begin{array}{l}8 \\
7.48\end{array}$ & $\begin{array}{l}106 \\
99.07\end{array}$ \\
\hline $\begin{array}{l}40 \\
8\end{array}$ & 118 & $\begin{array}{l}118 \\
100.00\end{array}$ & $\begin{array}{l}112 \\
94.92\end{array}$ & $\begin{array}{l}98 \\
83.05\end{array}$ & $\begin{array}{l}20 \\
16.95\end{array}$ & $\begin{array}{l}8 \\
6.78\end{array}$ & $\begin{array}{l}0 \\
0.00\end{array}$ & $\begin{array}{l}110 \\
93.22\end{array}$ \\
\hline $\begin{array}{l}30 \\
8\end{array}$ & $\bar{x}$ & $95.70 \%$ & 66.51 & 64.31 & 33.50 & 8.52 & 4.30 & \\
\hline
\end{tabular}


that do not react with the material to be sieved and the sieve. Elutants should be presaturated before use so that it does not act as a solvent for the material to be sieved. When the elutant is used as a solvent for fornulated material the elutant should be frequently changed so that upon drying the elutant does not leave a residue.

Sieve analysis should not be performed on material that has a length/width ratio greater than about 2 because the reliability of describing such a powder's $\pi$ is not good. Sample size should be based upon the amount of mater:al retained on each sieve and those that retain the most should be thoroughly studied to determine if retainment is due to overlaading. Additionally, sieves that retain the most matexial of near-mesh size should be observed to determine sieving time.

\section{Automatic Sieving Apparatus}

Particle size work at Pantex has been concerned with developing relatively efficient, accurate and reproducible methods of characterizing particulate explosive materials. One method developed at pantex and adopced by varions agencies has been wet sieve analysis ranging from 2000 to $1 \mu$. Due to powder distributions being in the $180 \mu$ and below range, a nest: 180 through $10 \mu$ electroform sieves are required for a standard distribution analysis. In order to conveniently perform a wet sieve analysis an instrument was devised to perform this test.

While using the sieving procedure, the motions needed to get a good analysis were studied to help give a clue to the agitation modes that would be netded for a sieve washer. The study revealed three motions were needed to avoid "kilinding," etc. and to obtain fast, reproducible results. These were: (1) rcitation; (2) a thumping action (vertical agitation); and (3) a slight vibration action on the side of the sieves. These motions were incorporated into the sieve washer shown in Fig. 1 .

This apparatus was designed to hold two stacks of 14 electroformed sieves. The controls for the different agitation modes are contained in the panel on the right of the apparatus. Point " $A$ " marks the controls for the rotation of the sieves. The vibration is introduced to the sieves by two means: (1) a vibrator "H" whose controls are mounted at "B" and (2) a set of tappers at "E" with controls at point "C". The vibrator "H" may be positioned at any of the 17 positions on bar " $D$ " to get the most efficient vibration into the sieves; also, the tappers may be removed or added to get the most efficient combination.

The regulators and speed adjustment are shown mounted on the control panel for each mode of agitation. This instrument has capabilities of horizontal motion obtained through the side motion of the entire sieve carriage and is not used due to overflow and a disadvantageous particle action.

The elutant is introduced into the sieves at "I" through a spray nozzle mounted in the cover over the sieves. The elutant is kept in a $\tan k^{\circ}$ connected to the sieve washer at point "F", a flow control value. 


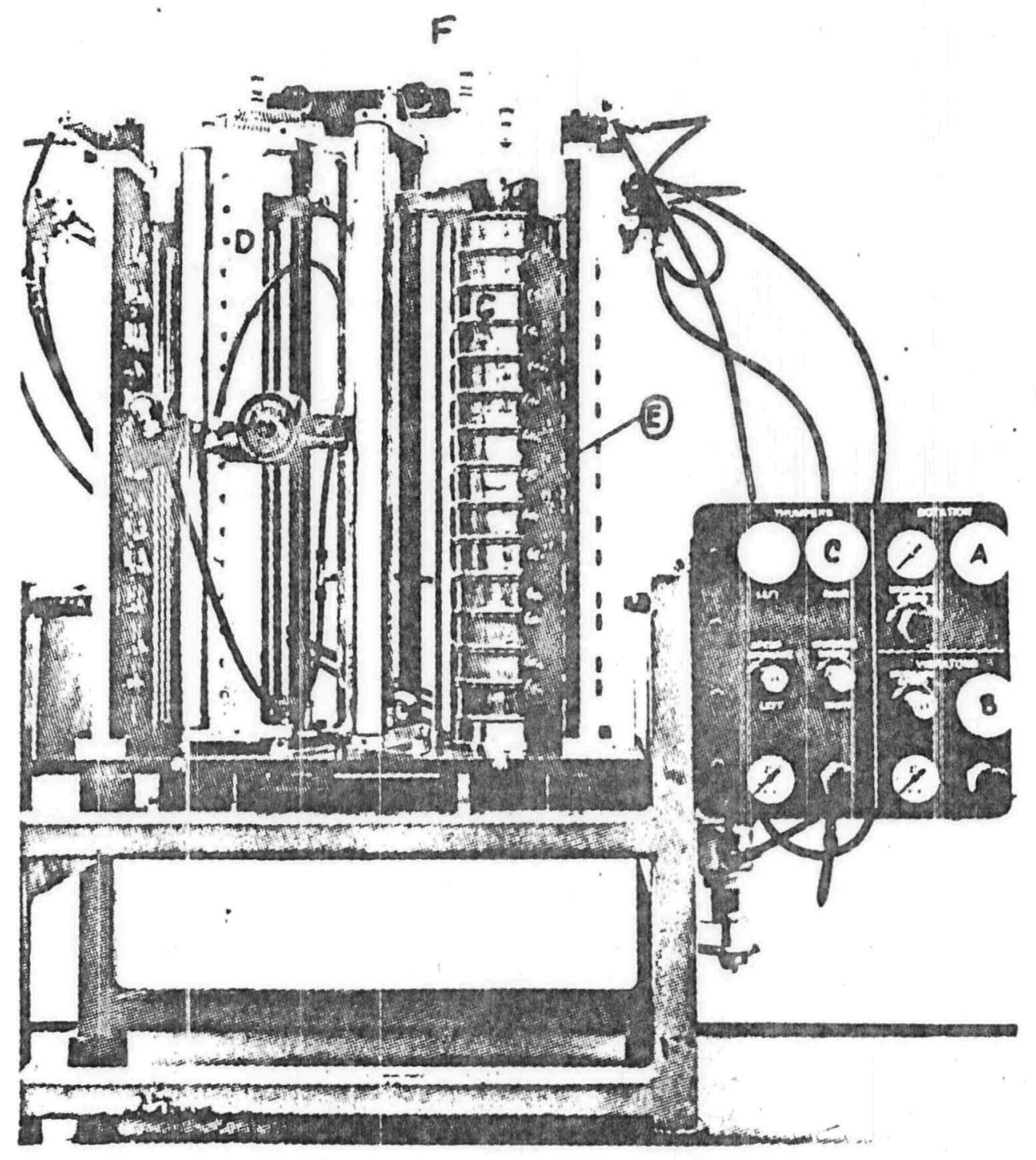

Figure 1. Pantex sleve washer with 14 sieves on one side. Control panel for the vibration and rotation modes of agitation shown at the left. 
Many experiments have been performed with this apparatus to find the sieving end-point at several control settings. A complete set of experiments to obtain control settings and flow rates were carried out.

The sieves used in the above-mentioned procedure, and in the sieve washer, need to have a small hole drilled in the side to prevent an elutant lock in the stack. Fig. 2 shows the preparation needed for the sieves; that is, crimp in the bottom lip and a hole in the top. This is needed to obtain a correct flow rate through the sieves.

The following procedure will describe the technique for sieving HMX. The apparatus meter settings will be covered in Part A and sample preparation, elutant, and sieving

A. Apparatus Meter settings

1. Pressure settings

(a) Rotation - approximately 60 psi

(b) Vibration - approximately 60 psi

(c) Tapper - approximately 35 psi. (about $450 \mathrm{cpm}$ )

(d) Elutant Tank - approximately 3 psi

2. Elutant Flow 170 to $200 \mathrm{ml} / \mathrm{min}$.

B. Procedure

1. Preparation of Sample

(a) Dry sample in vacuum oven for at least 2 hours to remove moisture.

(b) Place the sample in approximately $150 \mathrm{ml}$ of isobutyl acetate saturated with HMX.

(c) Put the sample in the ultrasonic vibrator until there are no visible signs of agglomerate (no longer than 5 minutes because of crystal destruction after this period). If periods of ultrasonic vibration are longer than 5 minutes in order to disperse sample then preshaking may be necessary. A wrist-action shaker does not damage the particles and extended time in the elutant does not seem to be detrimental.

(d) Keep the sample well agitated and covered untilused. 


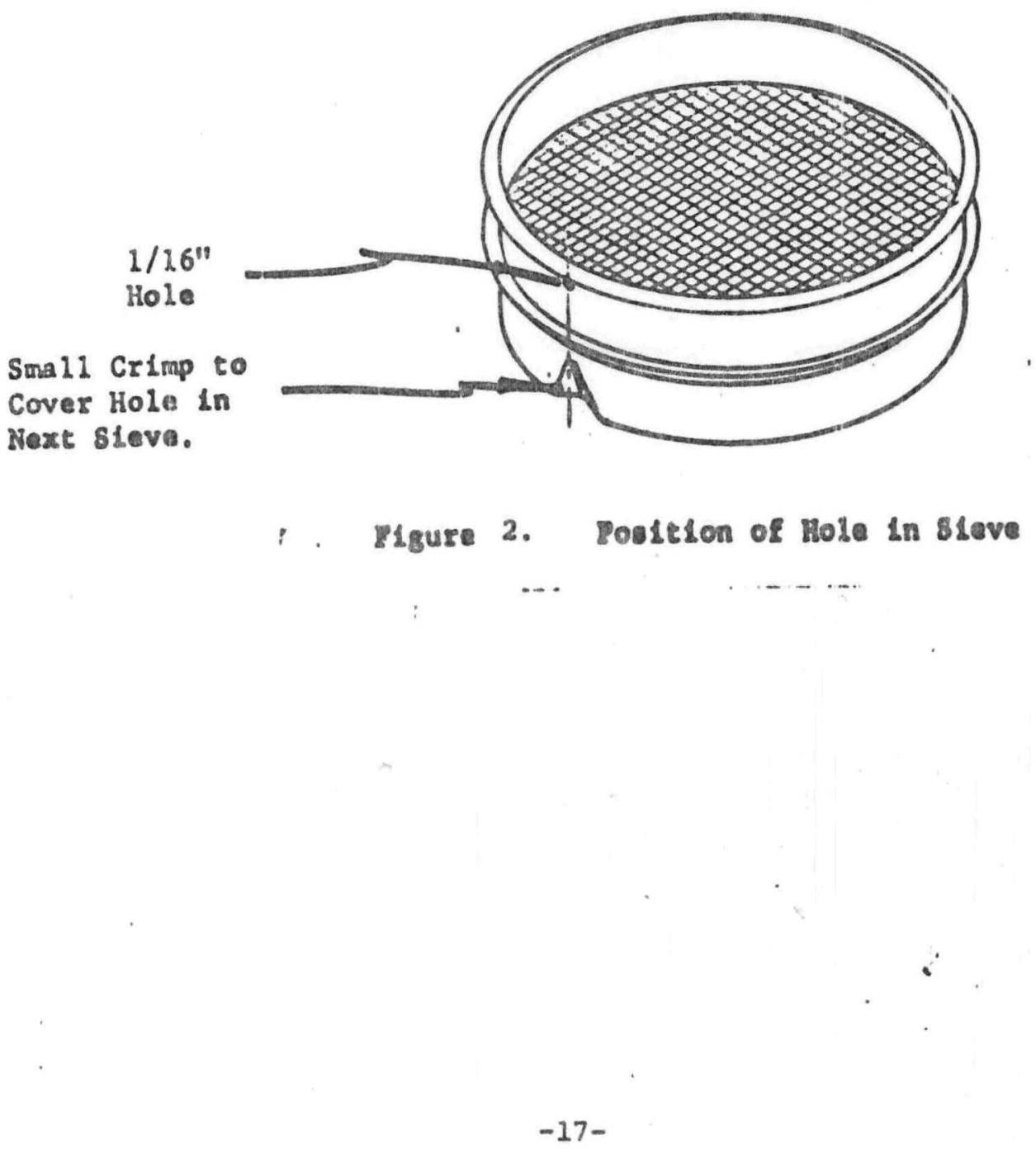


2. Preparation of Elutant

(a) Isobutyl acetate should be saturated with HMX for at least 24 hours before filtering.

(b) During HMX saturation if a dispersant is used then it should also be added before filtering so proper saturation of HMX may be accomplished.

(c) Saturate isobutyl acetate at temperature used for sieving.

(d) Filter the elutant to remove excessive HMX and dispersant.

(e) After filtexing avoid evaporation and temperature change.

3. Procedure for Sieving

(a) Place the weighted sieves (180 to $10 \mu$ ) in a stack on the Pantex Sieving Apparatus.

(b) Turn on rotation and vibration.

(c) Pour the sample through the stack of sieves.

(d) Wash sample container with 50 to $75 \mathrm{ml}$ of elutant as soon as possible.

(e) Turn on tappers and place cover over the sieve stack. Turn tappers on as soon as possible after putting sample in stack so the elutant does not build up on 10 and $20 \mu$ sieve.

(f) After most of initial elutant has passed $10 \mu$ sieve turn on elutant flow.

(g) Pass about $1300 \mathrm{ml}$ of elutant through the sieve stack.

(h) Turn off vibrators

(i) Additional elutant will pass through with rotation and tappers on. When flow ceases turn off tappers and rotation.

(j) Remove sieves and inspect for HMX splashed on sides and bottom of sieves. When necessary wash down the sides with a squeeze bottle and wash all HMX on the bottom of the sieve into the lower sieve. This may accumulate some elutant which may be removed by agitation.

(k) Centrifuge all elutant passing 10 sieves. :

(1) Dry sieves and centrifuge tubes in vacuum oven until all isobutyl acetate is removed.

(m) Weigh sieves and centrifuge tubes. 
(n) Calculat:e as percent retained or as percert passing.

4. Preparation of Freon B.F. for use as an elutant for the 2, 4, 6 and 8 sieves

(a) Using a given volume of Freon B.F., add $10 \%$ isobutyl acetate:

(b) Add 1 gram "Thixcin R" to each $500 \mathrm{ml}$ of solution and saturate on wrist action shaker for 20 minutes.

(c) Saturate with HMX and filter with No. 42 Whatman filter paper.

5. Procedure for sieving with $2,4,6$ and 8 sieves.

(a) Take a sample of the HMX that has been centrifuged and driech. (Retained as <10 $)$

(b) Weigh the total sample (may already have weight).

(c) From this sample, weigh oxt approximately 0.4 grams of HMX and put in $25 \mathrm{ml}$ of Freon B.F. in a weighted flask.

(d) Place the solution with HMX into ultrasonic vibrator and ag:tate until agglomerates have been broken apart (approximately 3 minutes;).

(e) Place the $10,8,6,4,2 \mu$ sieves on the sieve washer.

(f) Pour the HMX and solution into the lop sieve and start washing the HMX through the sieves. Tap on the side of the sieves to prevent clogging. Weigh the HMX residue and beaker. Keep covered with Iid or size large sieve to prevent evaporation.

(g) Wash the HMX in each sieve thoroughly as previously described for the $>10 \mu$. However elutant is added by squeezing bottle. Total added 100 to $200 \mathrm{mI}$.

(h) Centrifuge the material from the solution passing the $2 \mu$ sieve.

(i) Dry and weigh sieves and centrifuge tubes.

(j) Repeat steps (a) through (1) for two additional 0.4 gram samples from the large sample of HMX for repeats if necessary. 


\section{Ultrasonic Vibration}

Due to the severe agitation action of the ultrasonic vibrator, HMX crystals have been found to shatter and grind into smaller particles. Two experiments performed (June 1964) clearly show the attrition of HMX particles by prolonged ultrasonic vibration. The first experiment was to collect 5 grams of Class A HMX being retained on various sieves and then agitated in the vibrator for various times; the second was to use two HMX lots subjected to four different treatments in the vibrator.

The first experiment was carried out as follows: Iot 591-63 was sieved and 5 grams of HMX collected for the 250, 177, 125, 105, 88, 74,62 and $44 \mu$ sieves. Each 5 grams of HMX was placed in a $125 \mathrm{ml}$ flask with $100 \mathrm{ml}$ of elutant and vibrated for thirty minutes in 5 minute increments. The results indicate that particle attrition is dependent on size and duration. These results are shown in Fig. 3. Since coarser particles are the most effected, $60 \%$ of the oricginal $250 \mu$ particles reduced in size during the first 5 minutes. Another study was made to see the effects in 1 minute increments. The results are shown in 19 ig. 4; they indicate that the minimum time should be used.

The second experiment was set up with the following treatments for two undistributed batches:

1. Standard treatment of 5 minutes in ultrasonic e $35 \mathrm{ma}$ and flask on tank bottom.

2. Flask suspended in tank, shaken with wrist-action shaker while ultrasonic vibrator apparatus operates a $30 \mathrm{ma}$ for 2 minutes.

3. Violent ultrasonic vibrator action @ $50 \mathrm{ma}$ for 15 minutes

4. Wrist action shaker for 5 minutes.

The results are shown in Fig. 5 and 6 ; they show that the greatest distribution change occurred during treatment \#3. Microscopy indicated adequate dispersion of agglomerates achieved with treatments \#1 and \#2, while treatment \#3 shatters the particles and \#4 does not adequately disperse agglomerates. 
Fig. 3. HMX Particle Attrition During Various Ultrasonic Vibration Tines as Function of Particle Size

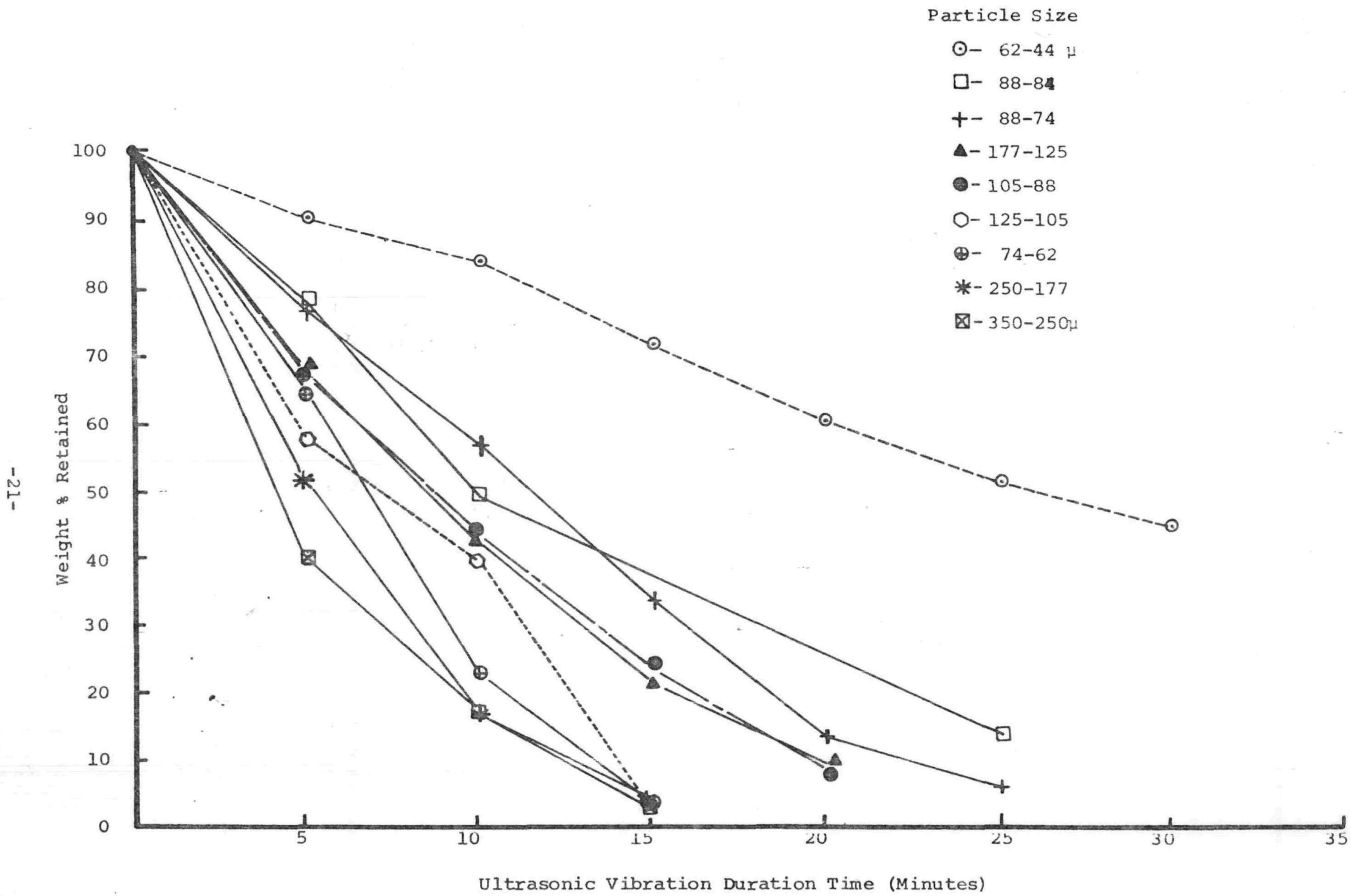


Fig. 4. HMX Passing $105 \mu$ retained on $74 \mu$ sieve and subjected to different times in ultrasonic vibrator.

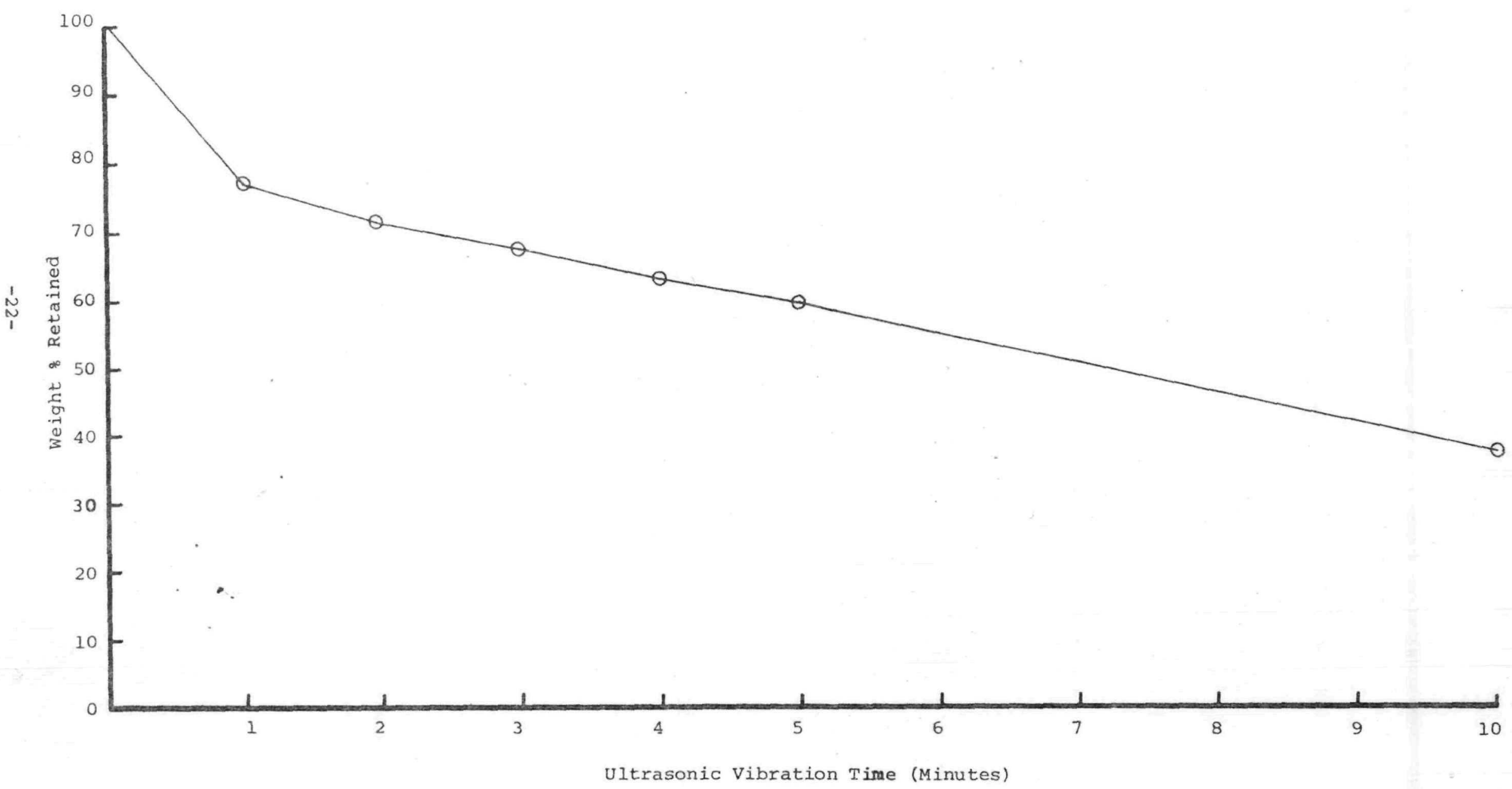



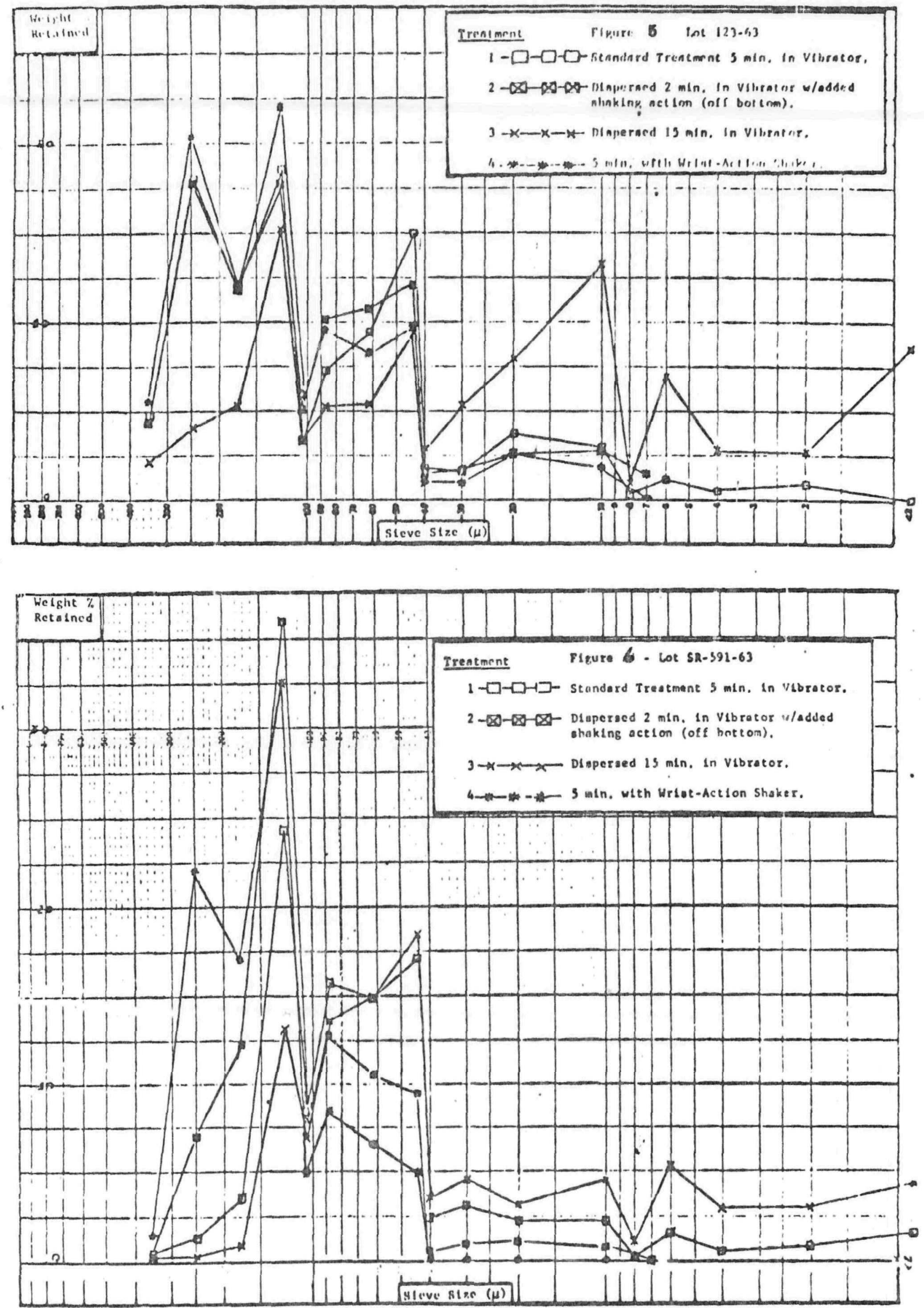
FERCULES SUPPLIED HMX HMX 961-5 E

CRYSTAL DENSIPY: 1.9000 G/CM=\$3

AO OF SIEVE AVALYSES = 1

NO DF SJB-AVALYSES FOH ANALYSIS $1=2$

ANALYSIS 1

ANALYSIS I

SIEVE SIZE

(MICRON)

180
150
130
100
90
80
70
60
50
40
30
20
10

10

i CENTRIFUGE

1

SIEVE SIZE (MICROV)

$B$
6
4
2

CENTRI U UEE

$\begin{array}{cc}\text { SIEVE WEIGHT } & \text { SIEVE W WEIGHT } \\ \text { (GKAM) } & \text { RETAINED(GRAM) } \\ 77.9791 & 77.9876 \\ 81.1302 & 81.1418 \\ 79.5839 & 79.5970 \\ 78.6729 & 78.6944 \\ 80.7288 & 80.7654 \\ 80.9937 & 81.0164 \\ 81.0242 & 81.0565 \\ 82.0554 & 82.0898 \\ 81.5646 & 81.5913 \\ 80.2376 & 80.2850 \\ 81.4280 & 81.4972 \\ 80.0283 & 80.1455 \\ 80.9327 & 81.3646\end{array}$

40,3530

78.6002

$78 \cdot 8314$

$77.80>3$

77.0840

\subsection{6}

77,7948

77.0344

11.0552 
REHCULES SUPPLIED HMX

HMX $961=5 E$

CRYSTAL DENSITY: 1.9000 G/CMEOH

$\triangle O$ OF SIEVE AVALYSES = 1

AO OF SIB-AVALYSES FUR ANALYSIS $1=$

ANALYSIS 1

-.........

SIEVE SIZE

(MICRON)

180
150
130
100
90
80
70
60
50
40
30
70
10

I CENTRIF UGE

1
SIEVE WEIGHT

(GRAM)

77.9791

81.1302

79.5839

78.6729

80.7288

80.9937

81.0242

82.0554

81.5646

80.2376

81.4280

80,0283

80.9327

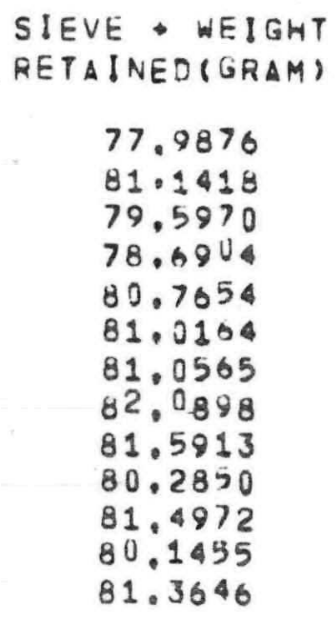

43,9635

46.3530

SIEVE SIZE (MICRCV)

$\begin{array}{lll}8 & 78.5858 & 78.0002 \\ 6 & 78.6690 & 78.8314 \\ 4 & 77.7948 & 77.8073 \\ 2 & 77.0344 & 77.0840\end{array}$

CENTRIF UGE

1 
HERCULES SUPPLIED HMX HMX $96175 \mathrm{E}$

CRYSTAL DENSITY: $1.9000 \mathrm{G} / \mathrm{CM}=3$

DATE: OY/O8/72

ANALYSIS 1

WEIGHT WIGHT
REYAINED WETAINED WEIGHT D
(SRAM)

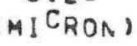

180
150
130
100
90
80
70
60
50
40
30
20
10
$<10$

0.0135

0.0158

0. 0173

0.0199

0.0272

0.0272

0.0227

0.0200

0.0332

0.0319

0.0336

0.0714

0.1201

2.3963

$$
\begin{array}{r}
0.41 \\
0.48 \\
0.52 \\
0.60 \\
0.82 \\
0.69 \\
0.62 \\
1.01 \\
0.97 \\
1.02 \\
2.16 \\
3.64 \\
14.52 \\
72.54
\end{array}
$$

\subsection{1}

0.89

1.41

2,01

2,84
3,52

4.15

5.15

6.12

7.14

9.30

12.93

27.46

ARITH REAN 10.2711

$\stackrel{1}{\omega}$

ELUDTANT USED

ISORUTYL ACETATE

METHOD JF SIEVING

PANPEX AUTOWASH

SIEVING PIME-IIN

25.

LLTRASCNIC VIZ TIME-MIN 1.0

SAMPLE HEIGHT-GRAM

$5.0166 \geq W E T$.

IYHE OF SIEVES USED

ELECTRO FORM
AVALYSIS?

WIGHT

WEIGHT HEIGHT \$ ACCUM.

REYAINED

RETAINED

REIGHT INLD

0.0077
0.0092
0.0123
0.0136
0.0235
0.0173
0.0197
0.0178
0.0247
0.0300
0.0619
0.1128
0.4481
2.4603

8.2526
8.0952

0,24

0.24
0.52

0.89

0.38

0.42

0.72

0.00

0.60

0,76

0,92

2.90

3.45

13,72

2,03

2,03

2.56
3.10

3.16

4.41
5.38

5.38
7.28

10.74

24,46

100.00

75,54

\begin{tabular}{|c|c|c|c|c|}
\hline $\begin{array}{r}0.173 \\
0.197 \\
0.147 \\
0.186 \\
0.104 \\
0.157 \\
0.020 \\
0.460 \\
0.209 \\
0.098 \\
0.200 \\
0.181 \\
0.798 \\
0.2995\end{array}$ & $\begin{array}{l}0,0212 \\
0,0250 \\
0,0296 \\
0,0335 \\
0,0507 \\
0,0400 \\
0,0403 \\
0,0510 \\
0,0566 \\
0,0636 \\
0,1333 \\
0,2329 \\
0,9278 \\
4,8626\end{array}$ & $\begin{array}{l}0.32 \\
0,38 \\
0,45 \\
0,51 \\
0,77 \\
0,01 \\
0,01 \\
0,78 \\
0,86 \\
0,77 \\
2,03 \\
3,55 \\
14.13 \\
76,03\end{array}$ & $\begin{array}{r}0.32 \\
0.70 \\
1.15 \\
1.06 \\
2.44 \\
3.05 \\
3.06 \\
4.84 \\
5.30 \\
0,27 \\
8,30 \\
11.84 \\
25.97 \\
100,00\end{array}$ & $\begin{array}{l}99,68 \\
99,30 \\
98,85 \\
98,34 \\
97,56 \\
96,95 \\
96,34 \\
95,56 \\
94,70 \\
93,73 \\
91.71 \\
88,16 \\
74,03 \\
0,00\end{array}$ \\
\hline
\end{tabular}

8.2526
8.0952

ISOBUTYL ACETATE

PANTEX AUTOHASH

25,0

1.0

5.0013 ZWEP

ELECTRO FORM
COMBINED ANALYSIS

DIFF IN COMJINED ULIGHT PERCENT PERCENT

DIFF IN COMB!NED WEIGHT DERCENT PERCEN

WT HET, RETAINED COARSER FINER

9.2677

9.1031 
HEHCULFS SUPPLIFD HMX $M M X 961.5 E$

CRYSYAL DENSIPY : $1.93006 / \mathrm{C}^{4}+3$

DO OF SIEVE AYALYSFS $=$ ?

NO OF SJB-AVALYSES FOR AUALYSIS $1=1$

10 OF SJBAAVALYSES FOR ANALYSIS $2=1$

ANALYSIS 1 ANALYSIS

SIEVE SIZE

(MICRON)

SIEVE WEIGHT

$\Delta$

CENTRIF JGE

ANALYSIS

a...... $=-\cdots$

SIEVE SIZE, SIEVF WIIGHT

180

180

130

40

80
70

60

bo

40
30

20

CENTHIFJGE (GKAM)

77.9833

89.1337

79.5901

$79.67 \times 8$

$72.67 \leqslant 8$

80.7310

80.9489

61.0253

A2.0614

51.5663

80.2395

81.4341

80.0314

80.0304

43.9542 (.STAH)

SIEVE - WEIGHT RETAINED (GRAM)

$$
\begin{aligned}
& 77.7968 \\
& 81.1495 \\
& 79.0074 \\
& 78.5957 \\
& 80.7582 \\
& 81.0216 \\
& 81.0469 \\
& 82.0940 \\
& 81.5922 \\
& 80.2731 \\
& 81.5055 \\
& 80.1515 \\
& 81.4191
\end{aligned}
$$

40.3505

SIEVE + WeITHT RFTAINED(GHAM)

77.9791

81.1300

$70.5 \times 48$

$7 \mathrm{~A} .5>75$

80.7245

80,9955

81.0240

82.0525

81.5032

80.2370

81.4285

80.0290
80.9341

77.9868

B1. $13 \forall 2$

79.5411

$78,08 \in 1$

10.1520

80.1520

अ1. 143

81.34 .37

प1. 5874

$01.587 y$

80.2610

01.4904

81.3422 
HERCULES SUPPLIED HMX HMX $96105 E$

CRYSTAL DENSIPY \& 1.9000 GICMEOS
DATE : $09108 / 72$
ANALYSIS 1 HEIGHT WEIGHT QEPAINED RETAINED WEIGHT: SIZE REPAINED (MICRON)

0.0184
0.0183
0.0211
0.0192
0.0294
0.0277
0.0257
0.0362
0.0341
0.0469
0.1066
0.1706
0.7505
3.8570
0.4676
1.9845
0.6717
0.7069
0.0263

$$
\begin{array}{r}
0.36 \\
0.35 \\
0,41 \\
0.37 \\
0.57 \\
0.54 \\
0,50 \\
0.70 \\
0.66 \\
0,91 \\
2.07 \\
3.31 \\
14.54 \\
74.72 \\
9.06 \\
38.45 \\
13.01 \\
13.89 \\
0.51
\end{array}
$$

\begin{tabular}{|c|c|c|}
\hline $\begin{array}{l}0,0154 \\
0,0140 \\
0,0177 \\
0,0182 \\
0,0236 \\
0,0226 \\
0,0253 \\
0,0367 \\
0,0323 \\
0,0407 \\
0,0751 \\
0,1154 \\
0,4658 \\
2,4027\end{array}$ & $\begin{array}{r}0.47 \\
0.42 \\
0.54 \\
0.55 \\
0.71 \\
0.58 \\
0.77 \\
1.11 \\
0.98 \\
1.23 \\
2.27 \\
3.49 \\
14.09 \\
72,09\end{array}$ & $\begin{array}{r}0,47 \\
0,89 \\
1,42 \\
1,98 \\
2,69 \\
3,37 \\
4,14 \\
5,25 \\
6,23 \\
7,46 \\
9,73 \\
13,22 \\
27,31 \\
100,00\end{array}$ \\
\hline
\end{tabular}

RETAINED

$$
\begin{array}{r}
0.36 \\
0.71 \\
1.12 \\
1.49 \\
2.06 \\
2.000 \\
3.10 \\
3.80 \\
4.46 \\
5.37 \\
7.43 \\
10.74 \\
25.28 \\
100.00 \\
34.34 \\
72.78 \\
85.80 \\
99.49 \\
100.00
\end{array}
$$

\begin{tabular}{|c|c|c|c|c|}
\hline $\begin{array}{l}\text { IFF IN } \\
\text { EIGHT }\end{array}$ & $\begin{array}{c}\text { COMB INED } \\
\text { HP, REY } \\
\text { (GRAM) }\end{array}$ & $\begin{array}{l}\text { WE IGHT } \\
\text { RETA!NFD }\end{array}$ & $\begin{array}{l}\text { PERCENT } \\
\text { COAASER } \\
\text { THAN }\end{array}$ & $\begin{array}{l}\text { PERCENT } \\
\text { F?NER } \\
\text { THAN }\end{array}$ \\
\hline $\begin{array}{l}=0.109 \\
=0.069 \\
=0.127 \\
=0.179 \\
=0,144 \\
=0.147 \\
=0.267 \\
=0,409 \\
=0.317 \\
=0,323 \\
=0.207 \\
=0,186 \\
0.448 \\
2.035\end{array}$ & $\begin{array}{l}0,0338 \\
0,0323 \\
0,0388 \\
0,0374 \\
0,0530 \\
0,0503 \\
0,0510 \\
0,0729 \\
0,0564 \\
0,0876 \\
0,1817 \\
0,2860 \\
1,2103 \\
0,2597\end{array}$ & $\begin{array}{r}0,40 \\
0,38 \\
0,46 \\
0,44 \\
0,03 \\
0,59 \\
0,00 \\
0,86 \\
0,78 \\
1,03 \\
2,15 \\
3,38 \\
14,36 \\
73,93\end{array}$ & $\begin{array}{r}0.40 \\
0,78 \\
1,24 \\
1,00 \\
2,31 \\
2,00 \\
3,50 \\
4,36 \\
5,15 \\
0,18 \\
8,33 \\
11.71 \\
20,07 \\
100,00\end{array}$ & $\begin{array}{l}99.60 \\
99,22 \\
96,70 \\
90.32 \\
99.69 \\
97.10 \\
96,50 \\
95.64 \\
94.85 \\
93.82 \\
91.67 \\
88.29 \\
73.93 \\
0.00\end{array}$ \\
\hline
\end{tabular}

$\triangle R I T H$ NEAN 13.1236 GEOM, MEAN,12.8901

\section{ELUDTAN USED.}

METHOD OF SIEVING

ISORUTYL ACETATE

PANTEX AUTOHASH

25.0

ULTRASONIC VIB TIME-MIN 1.0

SAMPLE HEIGHTOGRAM

8.0000 ZWET?

IYPE OF SIEVES USED

ELECTRO FORM
AVALYSIS 2

WEIGHY WEIGHT \$ ACEUM.
RETAINED RETAINED HEIGHT
(GRAMI

\subsection{7} 10,1807

ISOBUTYL ACETATE

PANTEX AUTONASH

25

1.0

$5.0340 \geq$ WET

ELECPROFORM
COMBINED ANALYSIS

9.2555

0.0899 
HERCULES SUPPLIED HAX HMX 961.5 E

CRYSTAL. DENSITY: 1,9000 G/CY"*3

NO OF SIEVE AVALYSES $=2$

10 OF SUB-AVALYSES FOH aNALYSIS $1=2$

NO OF SJB-AVALYSES FOF ANALYSIS $2=1$

ANALYSIS 1

MIEVE SIIE

SIEVE SIZ

SIEVE WEIGHT

SIEVE * HEIGHT

(GRAM)

RETAINEDIGRAM

180
150
130
100
90
80
70
60
50
40
30
20
10

77.9864

81.1350

79.5941

78.6801

80.7328

81.0030

81.0278
82.0632

82.0632

81.5687
80.2426

80.2426

80.0318

78,0048

81.1533

79,6152

78.6993

80.7022

81.0307

81.0535

82.0994
81,6028

80,2845

80.2845

80.2024

81.8904

CENTRI UGE

1.

43.9320

$47.78 \div 0$

SIEVE SIZE

(MICRCV)

\begin{tabular}{ll}
8 & 78.5865 \\
6 & 78.6675 \\
4 & 77.7927 \\
\hline
\end{tabular}

78.6675
77.7927

77.7927
77.0324

78.0078

78.7579

77.8233

CENTRI. UGE.

1.

11.0506

11.0518

ANALYSSIS 2

SIEVE SIZE

(MICRCV)

SIEVE WEIGHT

(GKAM)

SIEVE WEIGHT

RETAINED (GRAM)

180
150
130
100
90
80
70
60
59

81.1268

79.5845

78.5702

80.7244

1000

79.6022

$78.68=4$

80.7480
81.0180

80.9954

81.0180

81.0205081 .0478

82.05501040

21. 50.30 


$\begin{array}{lll}30 & 50.2359 & 80.2766 \\ 30 & 81.4278 & 81.5029 \\ 20 & 80.0281 & 80.1435 \\ 10 & 80.9369 & 81.4027\end{array}$

CENTRIFUGE 


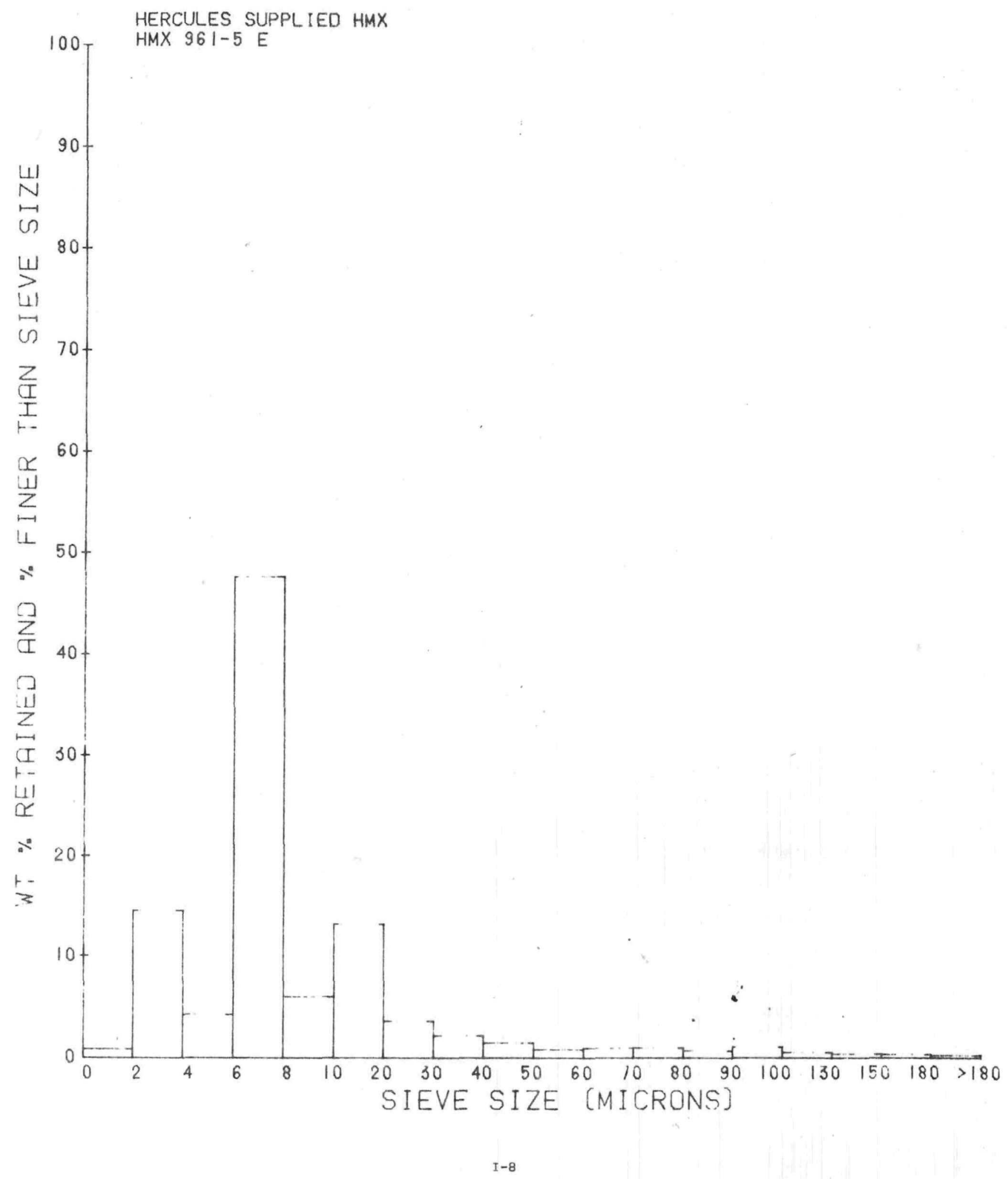




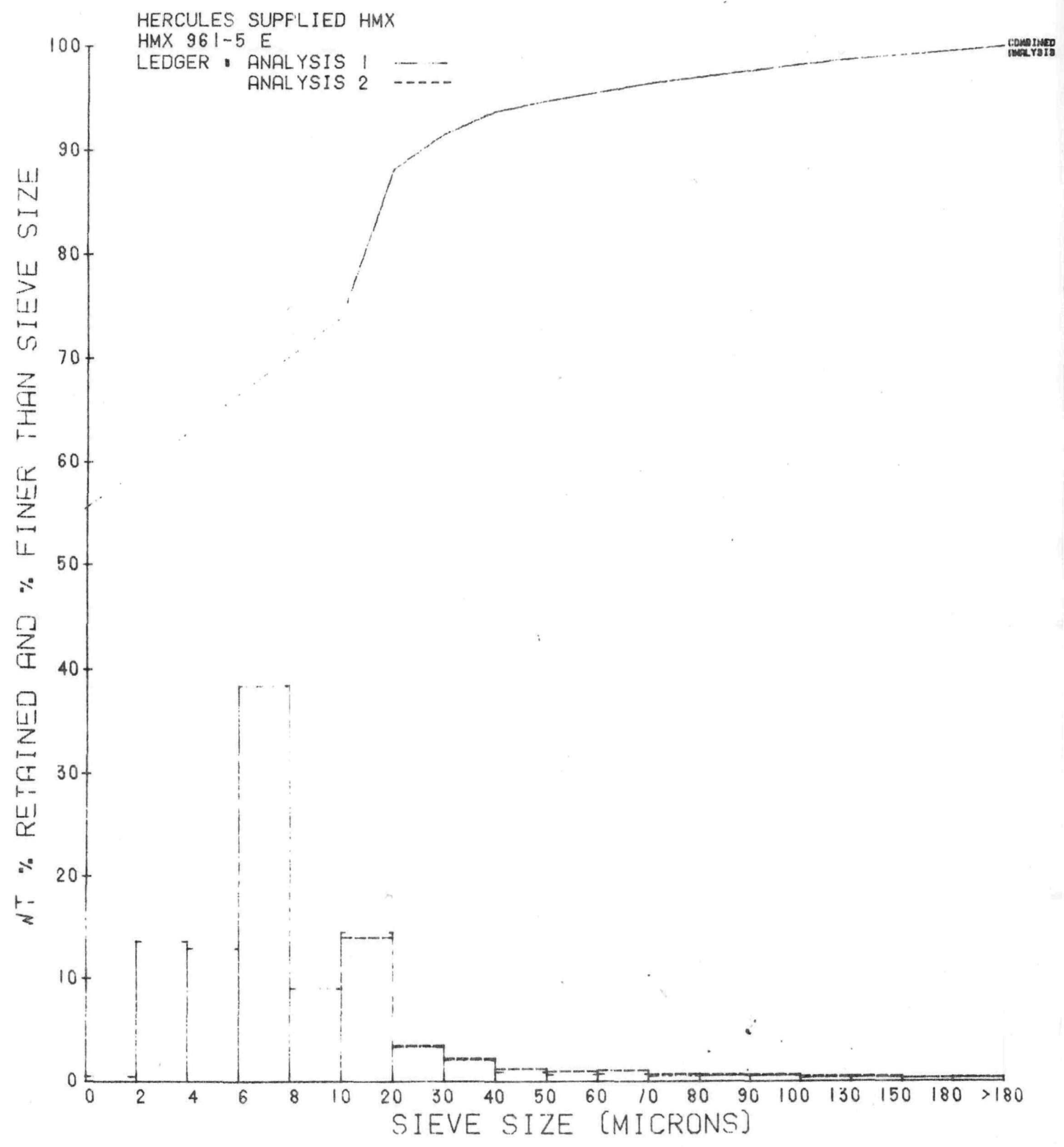




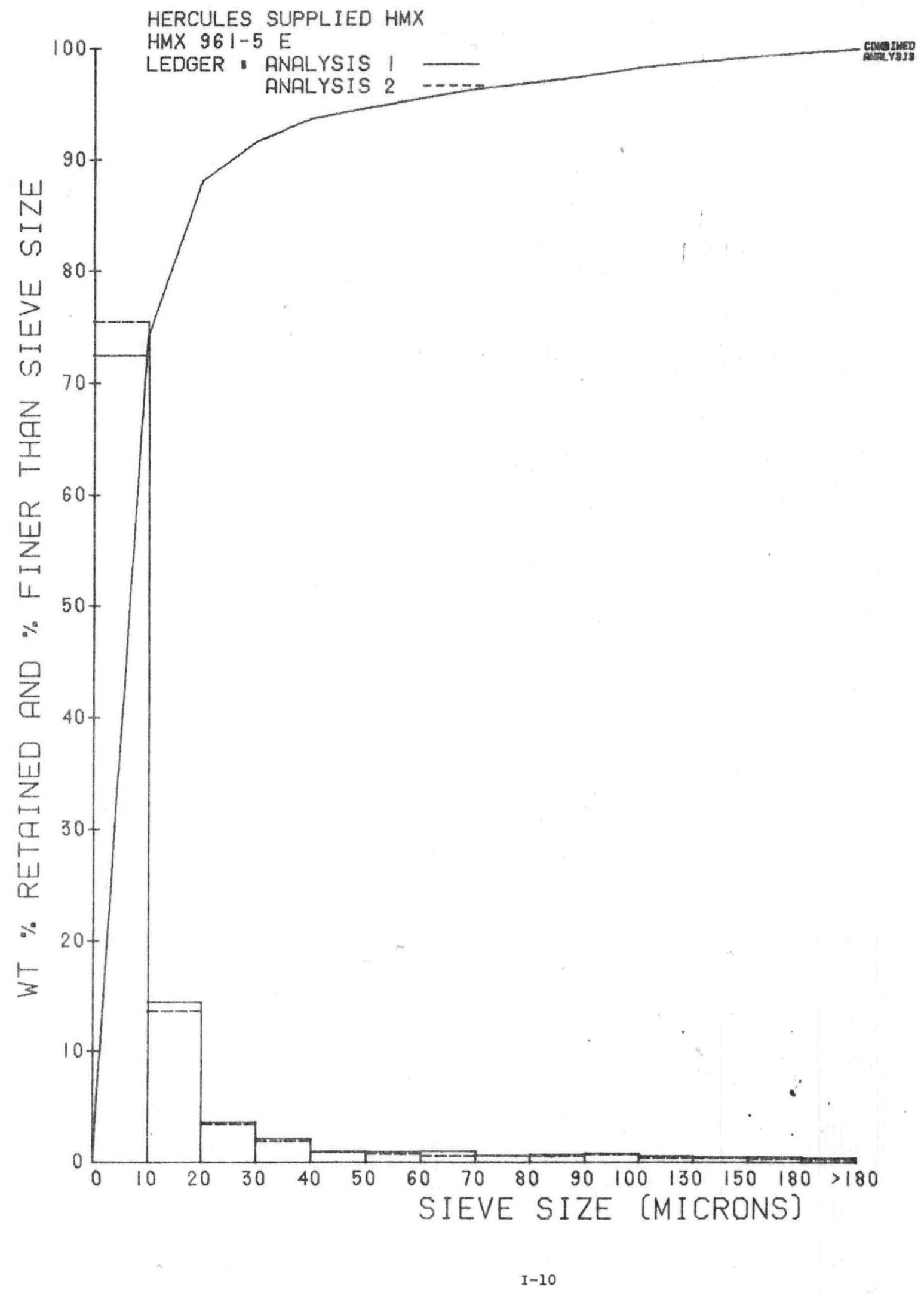


PARTICLE CHAAACTERIZATION - SIEVE ayabysIS

HERCULES SUPPLIED HMX

HMX 930.6 SAMPLE 1 GHGF 62.97

CRYSTAL DENSITY : 1,9000 G/CH\#3

DAPE, $09 / 08 / 72$

ANALYSIS 1

SIEVE HEIGHT HEIGHT

REPAINED REYAINED

$\begin{array}{rrrr}180 & 0.0197 & 0.50 & 0.50 \\ 150 & 0.0239 & 0.60 & 1.10 \\ 130 & 0.0231 & 0.58 & 1.08 \\ 100 & 0.0251 & 0.63 & 2.31 \\ 90 & 0.0362 & 0.81 & 3.23 \\ 80 & 0.0330 & 0.83 & 4.06 \\ 70 & 0.0376 & 0.05 & 5.01 \\ 60 & 0.0601 & 1.51 & 0.52 \\ 50 & 0.0884 & 2.23 & 8.75 \\ 40 & 0.1357 & 3.42 & 12.17 \\ 30 & 0.2959 & 7.46 & 19.62 \\ 20 & 0.2638 & 0.65 & 26.27 \\ 10 & 0.4856 & 12.24 & 38.51 \\ 110 & 2.4398 & 61.49 & 100.00\end{array}$

ARITH KEAN 15.5711

H GEOM. MEAN 15.3718

ELUDTANY USED

ISOBUTYL ACETATE

METHOD OF SIEVING

paniex aUtowash

SIEVING TIME-4IN

25.0

ULTRASONIC VIA PIME=MIN 1.0

SAMPLE WEIGHT=GRAM

5.0346 ZWET,

TYPE OF SIEVES USED

ELECTRO FORM 
HERCULES SUPPLIED HMX

HMX $930=6$ SAMPLE 1 GHGF 62.57

CAYSTAL DENSITY : 1.9000 G/CMO\#3

DAPE: $09 / 08 / 72$

NO OF SIEVE ANALYSES $\approx I$

NO OF SUB-ANALYSES FOR ANALYSIS $1=1$

ANALYSIS 1

- . . . . . . .

SIEVE S\ZE

(MICRON)

180
150
130
100
90
80
70
60
50
40
30
20
10

怘

í CENTRIFUGE

\section{SIEVE WEIGHT (GRAM)}

77.9760

81.1265

79.5824

78.6710

80.7249

80.9923

81.0214

82.0547

81.5609

80.2360

81.4229

80.0275

80.9342

1

43.9468

SIEVE W WIOHT RETA INED (GRAM)

$$
\begin{aligned}
& 77.9957 \\
& 81.1504 \\
& 79.6055 \\
& 78.6961 \\
& 80.7611 \\
& 81.0253 \\
& 81.0590 \\
& 82.1148 \\
& 81.8493 \\
& 80.3717 \\
& 81.7188 \\
& 80.2913 \\
& 81.4198
\end{aligned}
$$

46.3806 
HFRCULES SUPPLIED HAX HWX $930=6$ SAMPLE 1 GHGF $62-57$ CAYSTAL DEMBITY \& 1.9000 G/CM=M3

DATE: $09108 / 72$

ARALTSIS 1

\begin{tabular}{|c|c|c|c|}
\hline $\begin{array}{l}\text { SIEVE } \\
\text { SIZE }\end{array}$ & $\begin{array}{l}\text { UEIEAT } \\
\text { DEFA INED }\end{array}$ & $\begin{array}{l}\text { HEIGNT } \\
\text { HETAIMED }\end{array}$ & ACCUN \\
\hline
\end{tabular}

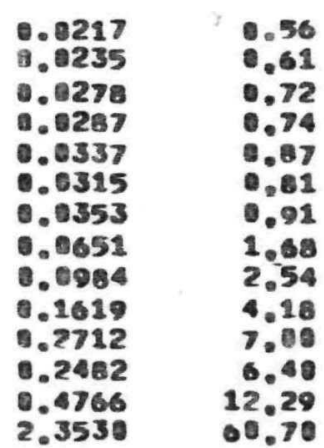

ARITH MEAN 15.3229

G GECW. MEAM 15.1215

El UDTAMT USED

ISOBUTYL ACETATE

METHOD OF SIEUING

PAMTEX Autouasm

SIEVIMG TIMË-ทIต

25,0

ULTRASONIC VIS TINE-FIM 1.0

SAMPLE WEIGAT-GRAM

5. $018 \geq 6 E T$.

IVPE OF SIEVES USED
AVALYSIS 2

\begin{tabular}{|c|c|c|}
\hline $\begin{array}{l}\text { HEIGMT } \\
\text { RETA I NED }\end{array}$ & $\begin{array}{l}\text { HEIGHI } \\
\text { RETAINED }\end{array}$ & $\begin{array}{l}\text { ACEUT, } \\
\text { WEIGNT \$ } \\
\text { RETAINED }\end{array}$ \\
\hline
\end{tabular}

0.56
1.17
1.89
2.62
3.49
4.31
5.22
0.90
9.43
13.61
20.61
27.01
39.30
100.08

0.918

0.48

0.45
0.51

0.51

0.73

0.66

1.06

3.39

2.19

4.10

6.67

6.71

13,04
61,40

$$
\begin{array}{r}
0.48 \\
0.93 \\
1.45 \\
2.04 \\
2.77 \\
3.44 \\
4.50 \\
5.89 \\
8.08 \\
12.18 \\
18.85 \\
25,56 \\
38.60 \\
100.00
\end{array}
$$

\begin{tabular}{|c|c|c|c|c|}
\hline $\begin{array}{l}0.079 \\
0.153 \\
0.203 \\
0.147 \\
0.138 \\
0.150 \\
0.154 \\
0.0293 \\
0.351 \\
0.072 \\
0.323 \\
0.306 \\
0.742 \\
0.705\end{array}$ & $\begin{array}{l}0,0405 \\
0,0412 \\
0,0479 \\
0,0519 \\
0,0623 \\
0,0574 \\
0,0769 \\
0,1193 \\
0,1839 \\
0,3223 \\
0,5320 \\
0,5104 \\
0,9861 \\
4,7528\end{array}$ & $\begin{array}{r}0.52 \\
0.53 \\
0.02 \\
0.07 \\
0.80 \\
0.74 \\
0.99 \\
1.53 \\
2.36 \\
4.14 \\
6.83 \\
6.56 \\
12.07 \\
61.05\end{array}$ & $\begin{array}{r}0,52 \\
1,05 \\
1,06 \\
2,33 \\
3,13 \\
3,87 \\
4,86 \\
6,39 \\
8,75 \\
12,89 \\
19,73 \\
20,28 \\
38,95 \\
100,00\end{array}$ & $\begin{array}{l}99,48 \\
98,95 \\
98,34 \\
97,67 \\
90.87 \\
96,13 \\
95,14 \\
93,61 \\
91.25 \\
87,11 \\
80,27 \\
73,72 \\
61.05 \\
0,00\end{array}$ \\
\hline
\end{tabular}

14.9922

14.7890

ISOBUTYL ACETATE

pantex autowash

25

1.0

$5.0151 \geq$ HET

ELECTRO FORH
COMBINED ANALYSIS

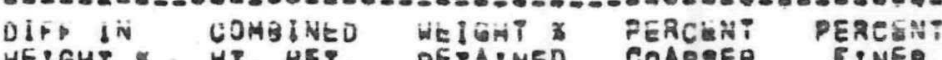

WEIGHT \$ WT, KET, REPAINED COAREER TINER

THAM THAN

55.6548

15.4525
99.48

.95

7.67

6,13

5.14

7,11

3,72

0,00 
HERCULLS SUDPLIED HMX

IMX 930.6 SAMPLE 1 GhGF 62.57

CRYSTAL DENSITY : 1.9000 li/C4E*3

UATE: $104 / 38 / 72$

IO OF SIEVE A VALYSES = ?

IO OF 5JH-AVA_YSES FOH ANALYSIS $1=1$

10 DF SJB-AVALYSES FOR SNALYSIS $2=1$

ANALYSIS 1

TER

(NICRCV)

SIEVE WEIGHT (GHAM)

SIEVE + WelGmi

81.1530

$80.7316 \quad 80.7053$

$81.0011 \quad 81.0320$

81.0265
82.0027

81.5064

$\begin{array}{ll}81.5864 & 81.6645 \\ 80.2398 & 80.4017\end{array}$

$\begin{array}{llll}H & 50 & 81.4340 & 81.7052 \\ \vdots & 20 & 80.0314 & 80,2796 \\ \vdots & 10 & 80.9431 & 81.4161\end{array}$

$\begin{array}{llll}H & 50 & 81.4340 & 81.7052 \\ \vdots & 20 & 80.0314 & 80,2796 \\ \vdots & 10 & 80.9431 & 81.4161\end{array}$

LENTRI JGE

43.9560

46.2896

${ }^{4 N A L Y S I S ?}$

C..........

SIEVE SIZE

(HICRCV)

SI IVVE WEIGHT

(GHAiA)

SIEVE + WE IGH

77.9758

$\begin{array}{rll}180 & 77.9758 & 77.0946 \\ 150 & 81.1258 & 81.1435 \\ 130 & 79.5021 & 79.0022 \\ 1100 & 79.6797 & 78.0939 \\ 90 & 80.7256 & 80.7542 \\ 80 & 80.9972 & 81.0171 \\ 70 & 81.0210 & 81.0020 \\ 60 & 82.0554 & 82.1070 \\ 50 & 81.5011 & 81.04=6 \\ 40 & 80.2359 & 80.3953 \\ 30 & 81.4272 & 81.0840 \\ 20 & 80.0272 & 80.2844 \\ 10 & 80.9337 & 81.4434\end{array}$

JENTRI JGE

43.9570

46,3508 
HERCULES SUPPLIED HMX

TMX $930=6$ SAMDLE 1 GHG 62.57

CRYSTAL DENSITY , 1,9000 G/C4NO3

DATE, $09 / 08 / 72$

NO OF SIEVE AVALYSES = ?

AO OF SJB-AVALYSES FOH ANALYSIS $1=2$

NO OF SJBAAVALYES FUR ANALYSIS $2=2$

ANALYSIS 1

\begin{tabular}{|c|c|c|}
\hline $\begin{array}{l}\text { SIEVE SIZE } \\
\text { (MICRCN) }\end{array}$ & $\begin{array}{l}\text { SIEVE WEIGWT } \\
\text { (GHAM) }\end{array}$ & $\begin{array}{l}\text { SIEVE WEIGHT } \\
\text { RETAINEDIGRAMI }\end{array}$ \\
\hline 180 & 77.9864 & 78.0102 \\
\hline 150 & 81.1350 & 81.1571 \\
\hline 130 & 79.5941 & $79.0100^{\circ}$ \\
\hline 100 & 79.5801 & 78.7118 \\
\hline$>0$ & 80.7328 & 80.7907 \\
\hline 80 & 81.0030 & 81.0571 \\
\hline 70 & 81.0275 & 81.0842 \\
\hline 60 & 82.0632 & 82.1843 \\
\hline 50 & 81.5047 & 81.7568 \\
\hline 40 & 80.2426 & 80.5953 \\
\hline 30 & 81,4340 & 62.0548 \\
\hline 20 & 80.0318 & 80.6225 \\
\hline 10 & 80,9450 & 82.0936 \\
\hline \multicolumn{3}{|l|}{ CENTRTH JGE } \\
\hline 1 & 43.9320 & 49.5897 \\
\hline $\begin{array}{l}\text { SIEVE SIZE } \\
\text { (MICREV) }\end{array}$ & . & \\
\hline A & 78.5875 & 78.6076 \\
\hline 3 & 78.6009 & 78.7735 \\
\hline 4 & 77.7948 & 77.8121 \\
\hline 2 & 77.0340 & 77.0072 \\
\hline
\end{tabular}

CENTRIF JGE

?.

1. 11.0533

11.0550

ANALYSIS 2

\begin{tabular}{|c|c|c|}
\hline $\begin{array}{l}\text { SIEVE SIZE } \\
\text { (MICRCV) }\end{array}$ & $\begin{array}{l}\text { SIEVE WEIGHT } \\
\text { (GRAM) }\end{array}$ & $\begin{array}{l}\text { SIEVE WEIGHT } \\
\text { RETAINED (UHAMI }\end{array}$ \\
\hline 180 & $77.9 \times 32$ & 78.0038 \\
\hline $1 ל 0$ & 81.1305 & 81.1539 \\
\hline $\begin{array}{l}130 \\
100\end{array}$ & $\begin{array}{l}79,5905 \\
78,6755\end{array}$ & $\begin{array}{l}79.01<0 \\
78,6958\end{array}$ \\
\hline $\begin{array}{l}90 \\
00\end{array}$ & $\begin{array}{l}80.7283 \\
80.9909\end{array}$ & $\begin{array}{l}80.7509 \\
81.0359\end{array}$ \\
\hline $\begin{array}{l}10 \\
60\end{array}$ & 81,0262 & 81.0018 \\
\hline$=n$ & $\begin{array}{l}82.0000 \\
04\end{array}$ & $24,0<28$ \\
\hline
\end{tabular}




$\begin{array}{lll}40 & 80.2301 & 80.3703 \\ 40 & 81.2357 & 81.7313 \\ 30 & 80.0301 & 80.2991 \\ 20 & 80.9425 & 81.4660 \\ 10 & & \end{array}$

CENTRIF JGE

1

43.9348

46.4234

SIEVE SIZE

(MICRON)

$\begin{array}{lll}8 & 78.5876 & 78.6116 \\ 5 & 78.0600 & 78.7817 \\ 4 & 77.7940 & 77.8232 \\ 2 & 77.0337 & 77.0607\end{array}$

CENTRIF UGE

11.0530 


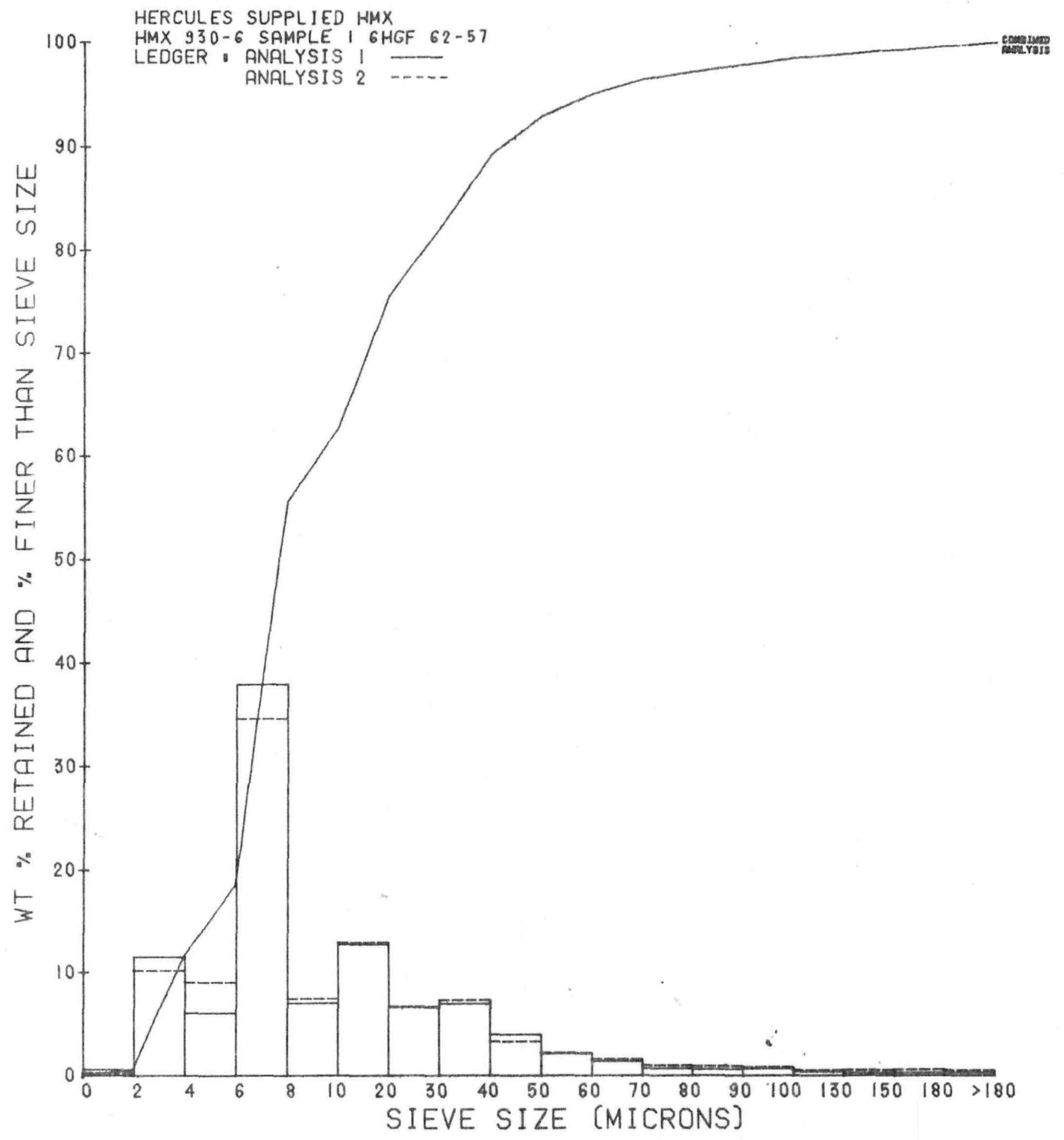




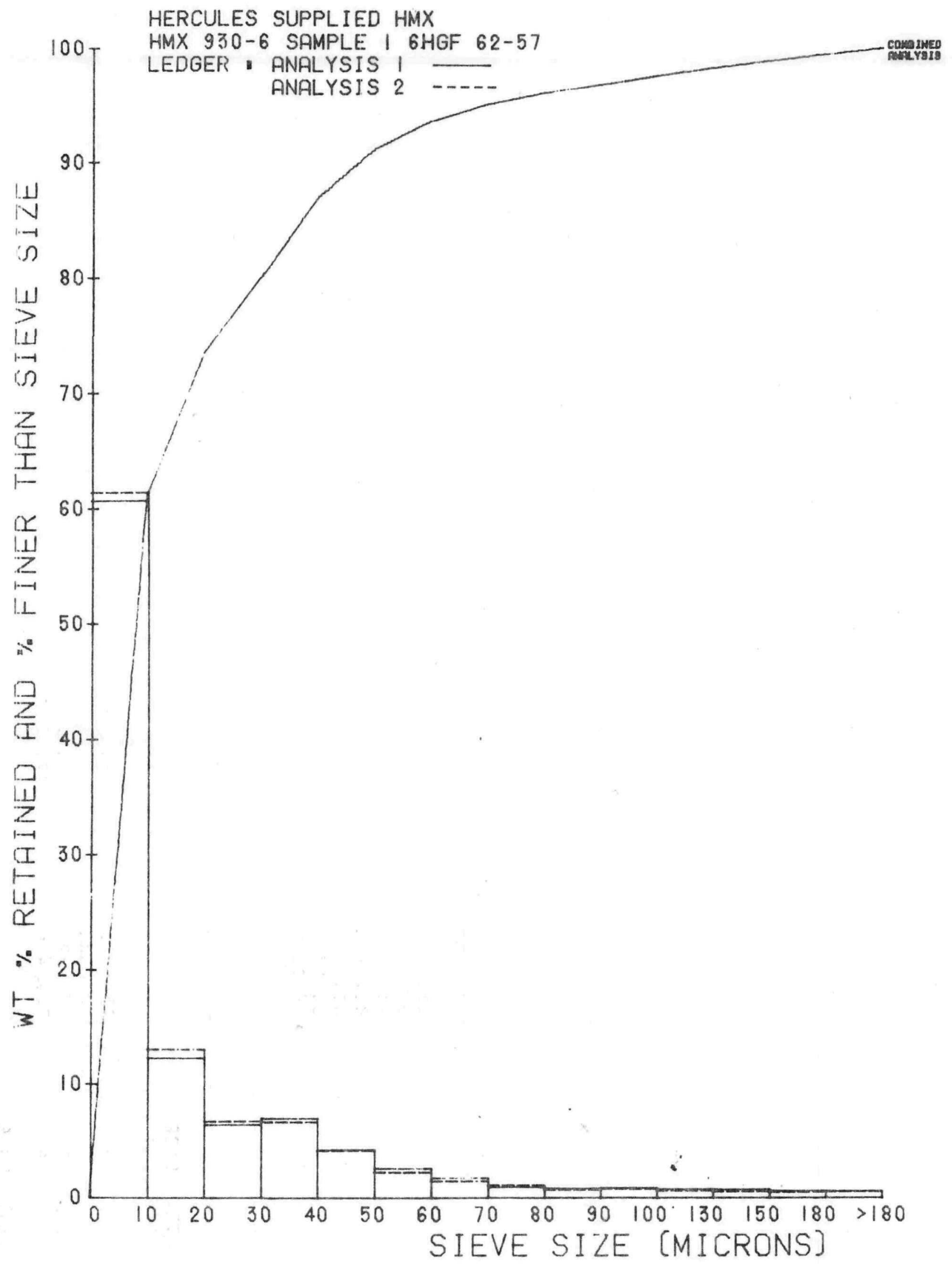




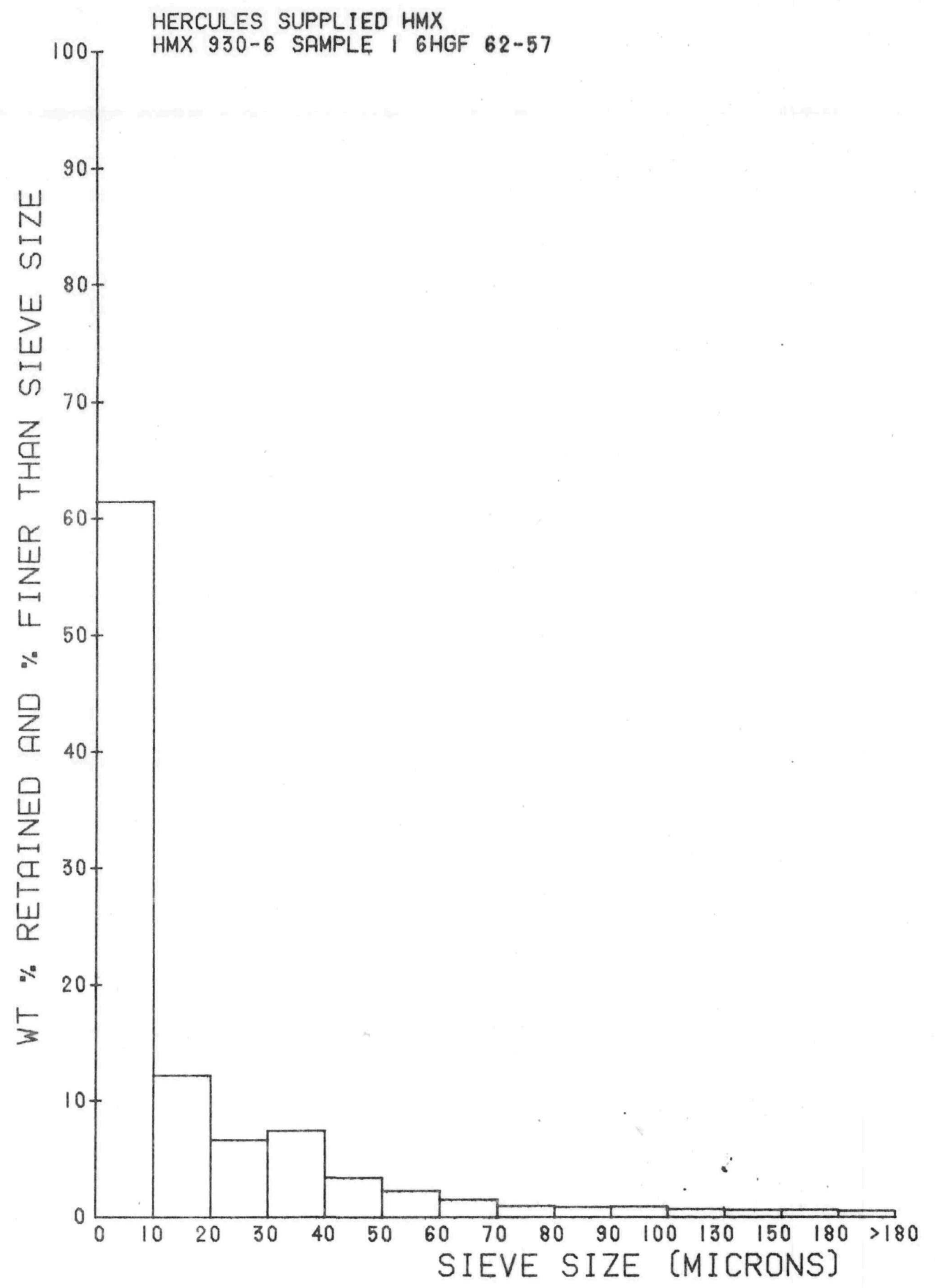


HFRCULES SUPPLIED POHDER - ERCULES HMK $t / N-14 A-61$

CRYSTAL DENSIPY: 1.9000 G/CM\#\#

ANALYSIS 1

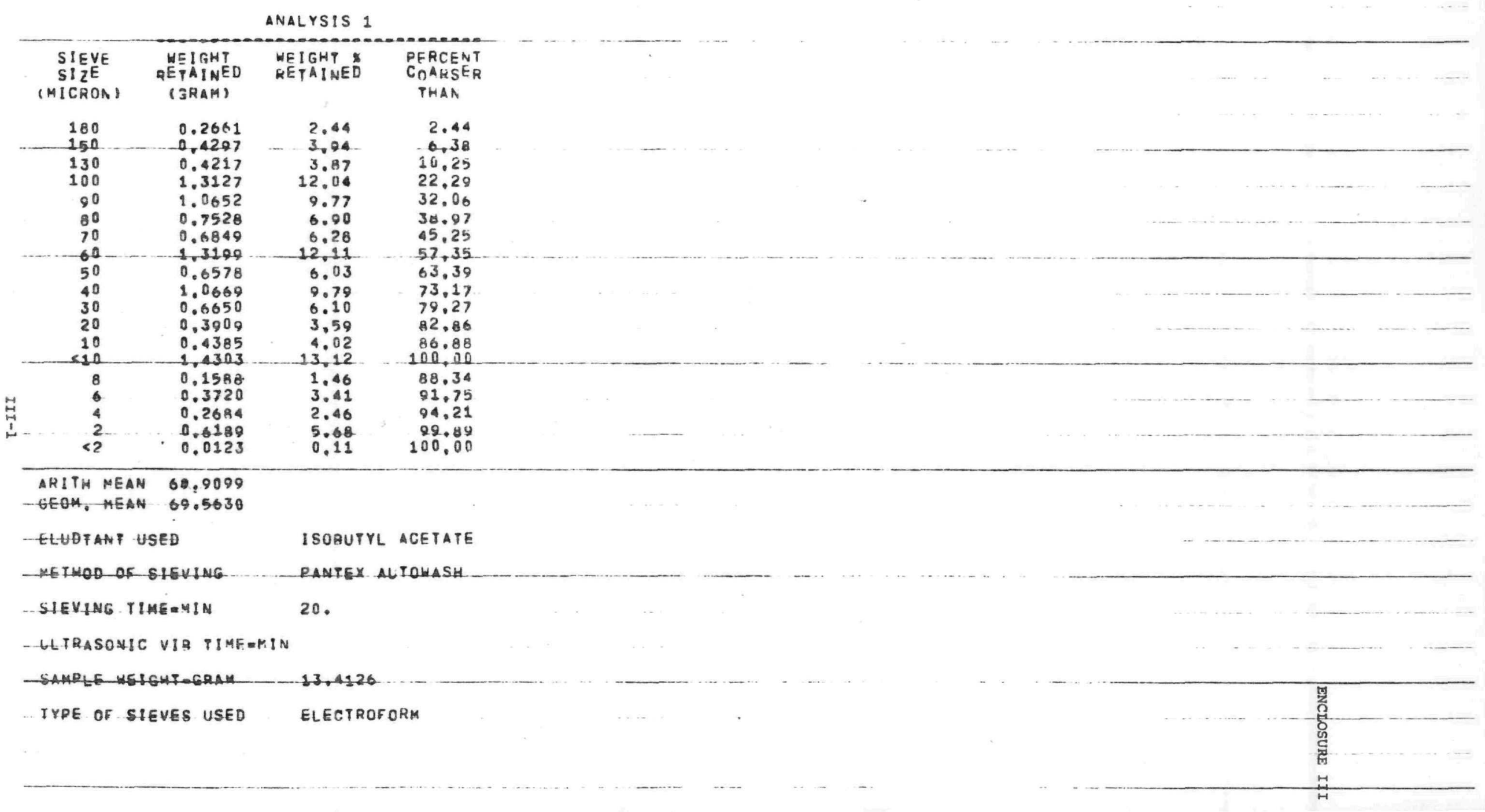


MERCULES SUPPLIED POWDER

HERCULES HAX L/N 148061

CRYSTAL DENSIIY: 1.9000 G/CM*\#3

NO OF SIEVE AVALYSES $=1$

NO OF SUB-ANALYSES FOR ANALYSIS $1=2$

ANALYSIS 1

- .........

SIEVE SIZE SIEVE WEIGHT SIEVE \$ WEIGHT

imicroa

(GRAM)

SIEVE $\triangle$ WEIGHT

\begin{tabular}{rrr}
180 & 77.2822 & 78.2553 \\
150 & 81.1360 & 81.5657 \\
130 & 79.5978 & 80.0195 \\
100 & 78.6819 & 79.9946 \\
80 & 80.7332 & 81.7984 \\
80 & 81.0034 & 81.7562 \\
70 & 81.0283 & 81.7132 \\
60 & 82.0666 & 83.3865 \\
50 & 81.5702 & 82.2280 \\
\hline 40 & 80.2448 & 81.3117 \\
\hline 30 & 81.0358 & 82.1008 \\
20 & 80.0337 & 80.4246 \\
10 & 81.2529 & 81.3914 \\
$H$ & & \\
\hline & &
\end{tabular}

43.0370

15,3673

SIEVE \$.12E

(M) CRON)

\begin{tabular}{rrr}
\hline 8 & 78.5825 & 78.6032 \\
6 & 78.6043 & 78.7128 \\
4 & 77.7896 & 77.8246 \\
2 & 77.0296 & 77.1103
\end{tabular}

CENTRIEUGE

1

11.0492

11.0508 
- HFRCULES SUPPLIED HMX WMX $L F N$ 148061

ANALYSIS I

SIEVE
SIZEE
(MICIGHT
DEYAINED WEIGHP
(SRAM)

$\begin{array}{rrr}180 & 0.1569 & 1.55 \\ 150 & 0.1665 & 4.60 \\ 130 & 0.1163 & 4.11 \\ 100 & 1.2214 & 12.05 \\ 90 & 0.9546 & 9.42 \\ 80 & 0.8560 & 6.47 \\ 70 & 0.7289 & 7.19 \\ -60 & 1.1517 & 11.36 \\ 50 & 0.6047 & -5.96 \\ 40 & 0.0062 & 8.94 \\ 30 & 0.6626 & 0.54 \\ 20 & 0.4174 & 4.12 \\ 10 & 0.4299 & 4.24 \\ -210 & 1.3648 & 13.46\end{array}$

H ARITH MEAN 6M.4604

GFOM, MEAN 69.1210

ELUDTANT USED

RETHOD OF SIEUING

SIEVING PIMEOMIN

ULTRASONIC VIG TIME-MIN 1.0

SAMPLE WEIGHT-GRAM

11.7338 ZWET.

IYPE OF SIEVES USED
ANALYSIS 2

Wh
WEIGHT RETAINED WEIGHT (GRAM)

$$
\begin{array}{r}
1.55 \\
0.15 \\
10.26 \\
22.30 \\
31.72 \\
38.19 \\
45.38 \\
56.71 \\
62.71 \\
71.64 \\
78.18 \\
82.30 \\
86.54 \\
100.00
\end{array}
$$

\begin{tabular}{|c|c|c|c|c|}
\hline $\begin{array}{r}-0.340 \\
0.451 \\
-0.161 \\
0.032 \\
-0.447 \\
0.514 \\
=0.175 \\
=0.500 \\
=0.120 \\
0.226 \\
-0.140 \\
=0.185 \\
0.068 \\
0.277\end{array}$ & $\begin{array}{l}0.3511 \\
0.0935 \\
0.8554 \\
2.4577 \\
1.9694 \\
1.2689 \\
1.4867 \\
2.3720 \\
1.2307 \\
1.0026 \\
1.3495 \\
0.0600 \\
0.8592 \\
2.0700\end{array}$ & $\begin{array}{r}1.72 \\
6.37 \\
4.29 \\
12.03 \\
9.64 \\
6.21 \\
7.28 \\
12.01 \\
6.02 \\
8.02 \\
6.61 \\
4.21 \\
4.21 \\
13.07\end{array}$ & $\begin{array}{r}1.72 \\
6.09 \\
10.28 \\
22.31 \\
31.95 \\
38.17 \\
45.44 \\
57.06 \\
63.08 \\
71.91 \\
78.51 \\
12.72 \\
86.93 \\
100.00\end{array}$ & $\begin{array}{l}98.28 \\
23.01 \\
89.72 \\
27.69 \\
68.05 \\
61.83 \\
54.58 \\
42.04 \\
36.92 \\
28.09 \\
21.49 \\
17.28 \\
13.07 \\
0.00\end{array}$ \\
\hline
\end{tabular}

\begin{tabular}{rrr}
0.1942 & 1.89 & 1.89 \\
0.4270 & 4.15 & 6.04 \\
0.4391 & 4.27 & 10.31 \\
1.2363 & 12.02 & 22.32 \\
1.0148 & 9.86 & 32.18 \\
0.6129 & 5.96 & 38.14 \\
0.7578 & 7.37 & 45.51 \\
1.2203 & 12.80 & 57.37 \\
\hline 0.6260 & 6.08 & 63.45 \\
0.8964 & 8.71 & 72.16 \\
0.6869 & 6.68 & 78.84 \\
0.4426 & 4.30 & 83.14 \\
0.4293 & 4.17 & 87.31 \\
1.3052 & 12.60 & 100.00
\end{tabular}

\subsection{0}

68.6719
COMBINED ANALYSIS

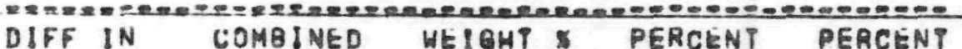

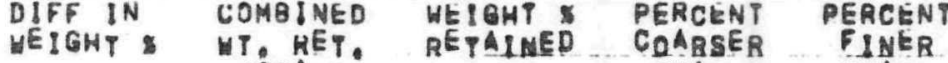

(GRAM)

\section{8,7372}

68,3984

ISOBUTYL ACETATE

PANTEX AUTOHASH

20.0

1.0

12,0013 ZWET

ELECTRO FORM 
HERCULES SUPPLIFD HMX

+MX LAN $14 \theta-61$

CRYSTAL DENSITY: 1.9000 G/CM=*3

DATE : 09106172

AO DF SIEVE AVALYSES =

AO OF SUB-AVALYSES FUR ANALYSIS $1=1$

NO OF SJB-ANALYSES FUF ANALYSIS $2=1$

ANALYSIS 1

SIEVE SIR

SIEVE SIZF

(MICROV)

SIEVE WEIGHT

SIEVE + WEIJHT

(SRAM)

RETAINEDQGRAM

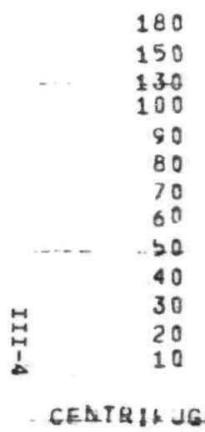

77.9320

81.1320

79.5881

78.6753

80.7312
20.9975

B1.0250

82.0003

81.5050

B०.2 उคด

81.4303

BO 0.0300

80.9374

78.1300

81.5905

d0. 0044
$79.840 ?$

81.0856

01.0535

81.7539

83.2120

02.1077

$81.14=0$

82.0969

80.4474

$41.36 / 3$

CEDTRIK

43.9530

45.3178

ANALYSIS 2

SIEVE SIZE

SIFVE WEIGHT (GKAM)

SIEVE - WEIGHT

(MICRON).

77.4800

GETA INED (GHAM)

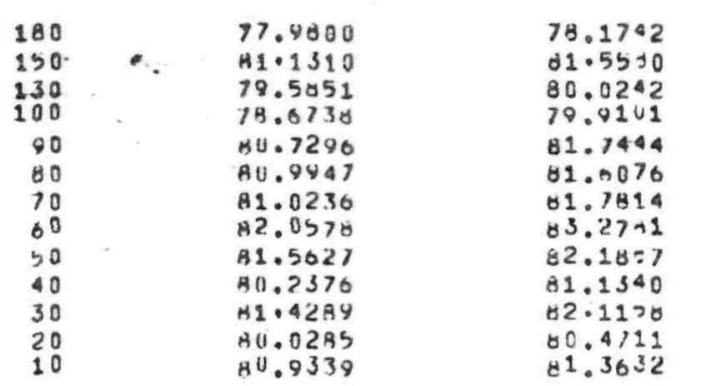

CENTRIF JGE

43,9021

45,2013 
HERCULES SUPP.IFD HMX rMX LN $148-61$

CRYSTAL DENSITY : 1.9000 II/CM

ANALYSIS 1

WEIGHT WIGHT B ACLLM.
(IKAM)

2.27
4.41

3.95

12.24

9.79

0.112

11.46

0.75

9.115

3.39

3.96

3.96
13.14

0.5264

点

2.27
0.69
10.64
22.88
32.07
30.64
45.70
57.16
33.91
72.96
74.34
82.90
80.86
100.00

WATE : $0 Y / 06 / 72$

COMBINED ANALYSIS

WEIGHT WEIGHT
KETAINED RETUM.
(GRAM)

DIFF IN LIMJIVED WEIGHT \& PERCENT PERCENT

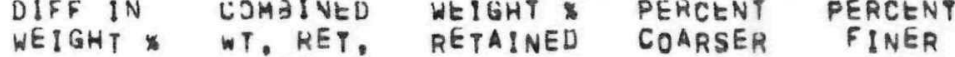

(GRAM)' THAN PHAN

$\begin{array}{rrr}0.1936 & 1.45 & 1.95 \\ 0.4602 & 4.03 & 6.58 \\ 0.4100 & 4.12 & 10.70 \\ 1.2156 & 12.23 & 22.93 \\ 0.9772 & 9.83 & 32.76 \\ 0.0927 & 0.97 & 39.73 \\ 0.0423 & 0.46 & 46.19 \\ 1.1581 & 11.65 & 57.35 \\ 0.0353 & 0.39 & 04.24 \\ 0.0892 & 8.95 & 73.18 \\ 0.0641 & 0.03 & 79.80 \\ 0.3730 & 3.75 & 83.62 \\ 0.4079 & 4.10 & 87.72 \\ 1.2205 & 12.28 & 100.00 \\ 0.1208 & 1.22 & 88.94 \\ 0.0130 & 5.16 & 94.10 \\ 0.1971 & 1.98 & 96.00 \\ 0.3717 & 3.74 & 99.82 \\ 0.0179 & 0.19 & 100.00 \\ 70.7427 & & \end{array}$

70.7827
, 0.4293

0.327
-0.215
-0.177
0.015
-0.042
-0.947
0.544
-0.189
0.356
0.101
$=0.293$
-0.196
-0.147
0.862

0.4962

1.0475

0.9352

2.8445

2.2795

1.4938

1.5743

2.6830

1.5329

2.0927

$1, \supset 140$

0,8402

0.9343

2.9687

2.13
4.51

4.02

$12: 24$

0,81

0.43

6.77

11.54

6.60

9,00

0,51

3,64

4.02
12.77

2.13

97.87

0,64

10.07

22,90

32.71

39,14

45,91

57.45

64.05

73.05

79.57

$83: 21$

87.23

$100 \% 00$

93,36

89.33

77.10

67.29

60.86

54,09

42.55

35.95

20,95

20.43

16.79

12.77

ARITH MEAN 67.6118

GECM, MEAN 69.2763

ELLDTANT USED

ISORUTYL ACFTATE.

MFTHOD OF SIEVING

PANTEX ALTOWASH

SIEVING TIME-4IN

20.3

LLTHASOVIS VIT IIME-MIN $1 . \bar{U}$

SAMPLE WEIGAT-GRAY

15. 2000 ? WET

IYPE OF SIEVTS IISE[]

ELECTRO FOHM

ISOUUTYL ACETATE

PAVTEX AUTOWASH

20.0

1. 0

$11,7131 \geq w E 1$,

ELECTKO FURM 
TFRCULES SUPPLIED HMX

$\rightarrow M *$ LAN $14 \theta-61$

CRYSTAL DENSITY: 1.9000 G/CMNO3

NATE: $04 / 00 / 72$

NO OF SIEVE AVALYSFS = ?

AO OF SJB-AVA_YCES FIR AVALYSIS $1=1$

NO OF SJB-AVA YSES FUH AVALYSIS $2=$ :

ANALYSIS 1

-...........

SIEVE SIZE

(MICROV)

SIEVE WEIGHT (GHAM)

GFT THEIGIT

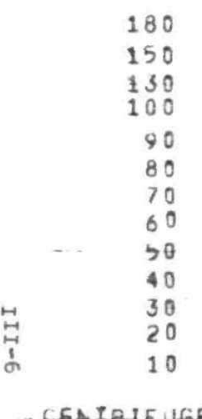

77.9904

Y $1.13 B_{1}$

79.5873

46. $731 \mathrm{~B}$

A1. 01240

R1. 1.0240

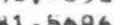

A1. 2441

A.

81.4352

0.0524

$75.29: 5$

01.1234

80.1225

की

82.0341

01.900

83.5011

82.4012

81.4476

82.2851

$82.28=1$

A1 477 to

- geafaIFuge

4.3.9.535

45.6747

ANALYSIS? -...........

SIEVE SIZE

(MICRON)

SIEVE WETGHT

(GKAM)

SIEVE WEIGHT

77.9830

A $1.13+2$

81.1372
70.5398

74.6758

00.7243

कण. 9943

82.0673

80.2380

$81.430 A$

B. 0300

80.9390

RETAINEOULHAMI

\subsection{2}

61.5914

$70.099 \mathrm{H}$

79,4914

01.7035

81.0910

11.0004

त3. 2246

02.2035

01.1218

82. 1949

00.4050

$41.347 \%$

CENTRIF JGE

1

43.9352

$45.12 \div 7$

SIEVE SIZE

(MICRCV) 


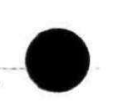

$\begin{array}{llr}8 & 78.5805 & 78.5987 \\ 6 & 78.6022 & 78.7395 \\ 4 & 77.7873 & 77.8170 \\ 2 & 77.0282 & 77.0842\end{array}$

GENTRIFUGE

1

11.0475

11.0502

点 


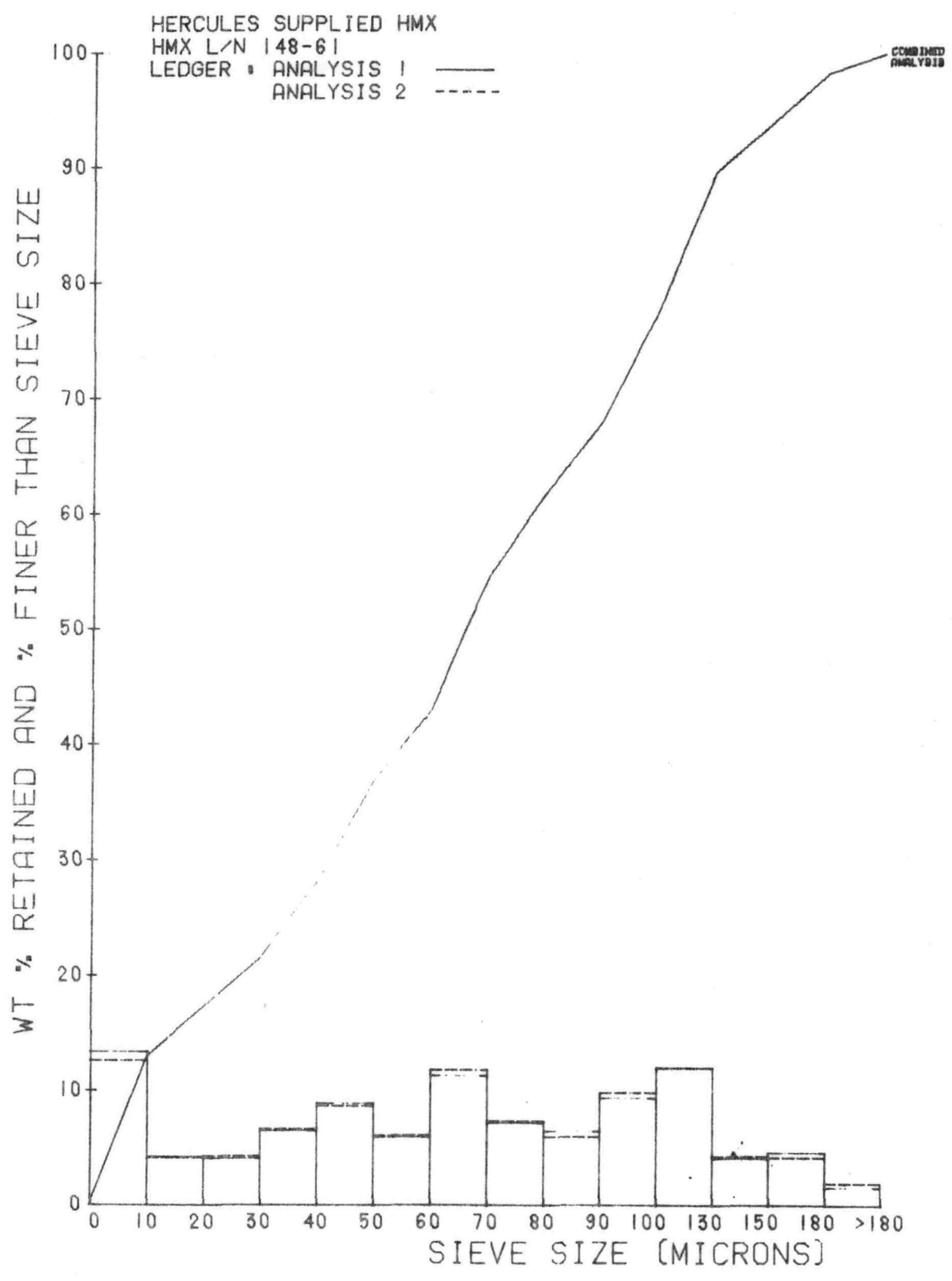




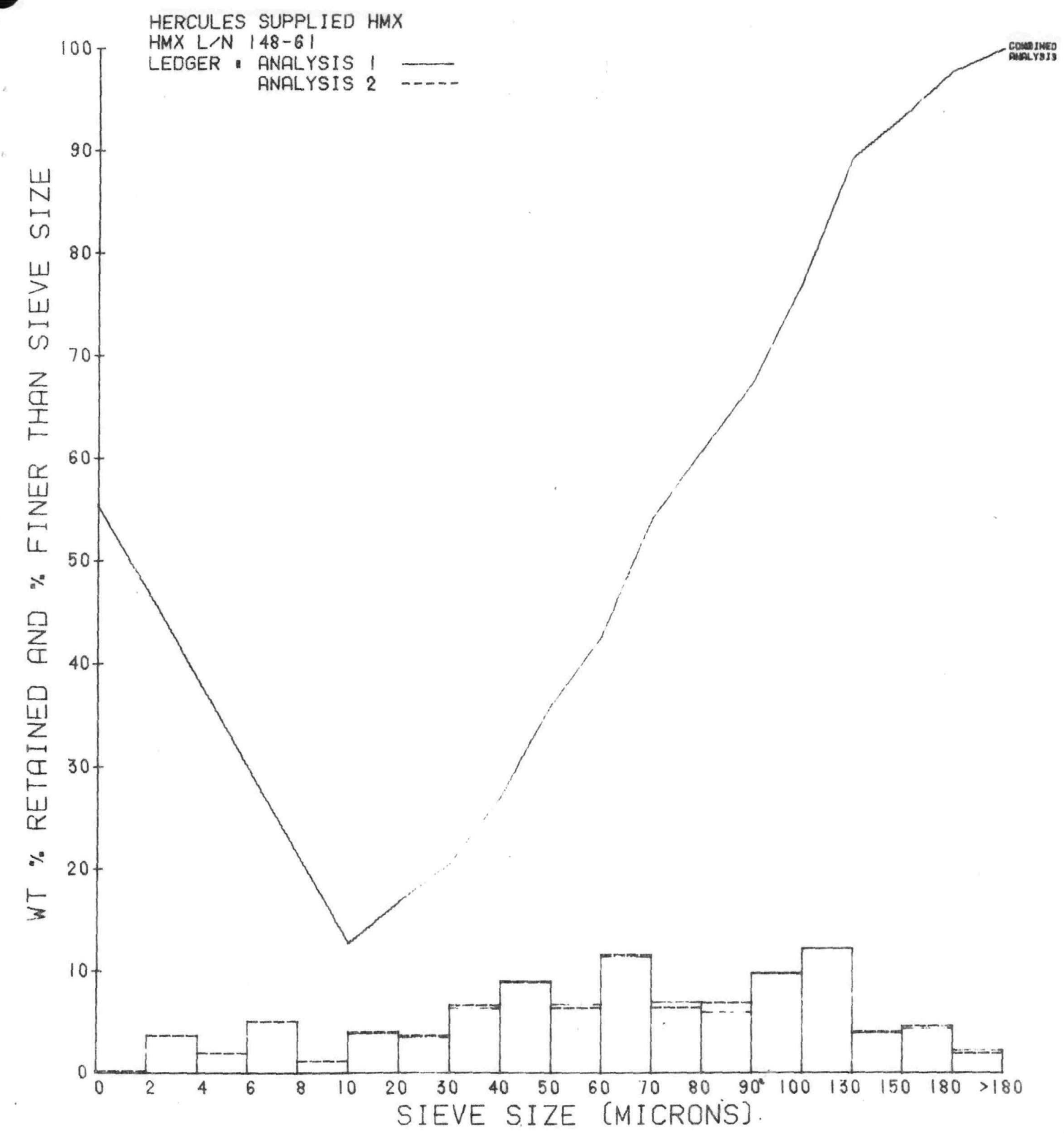

III -9 


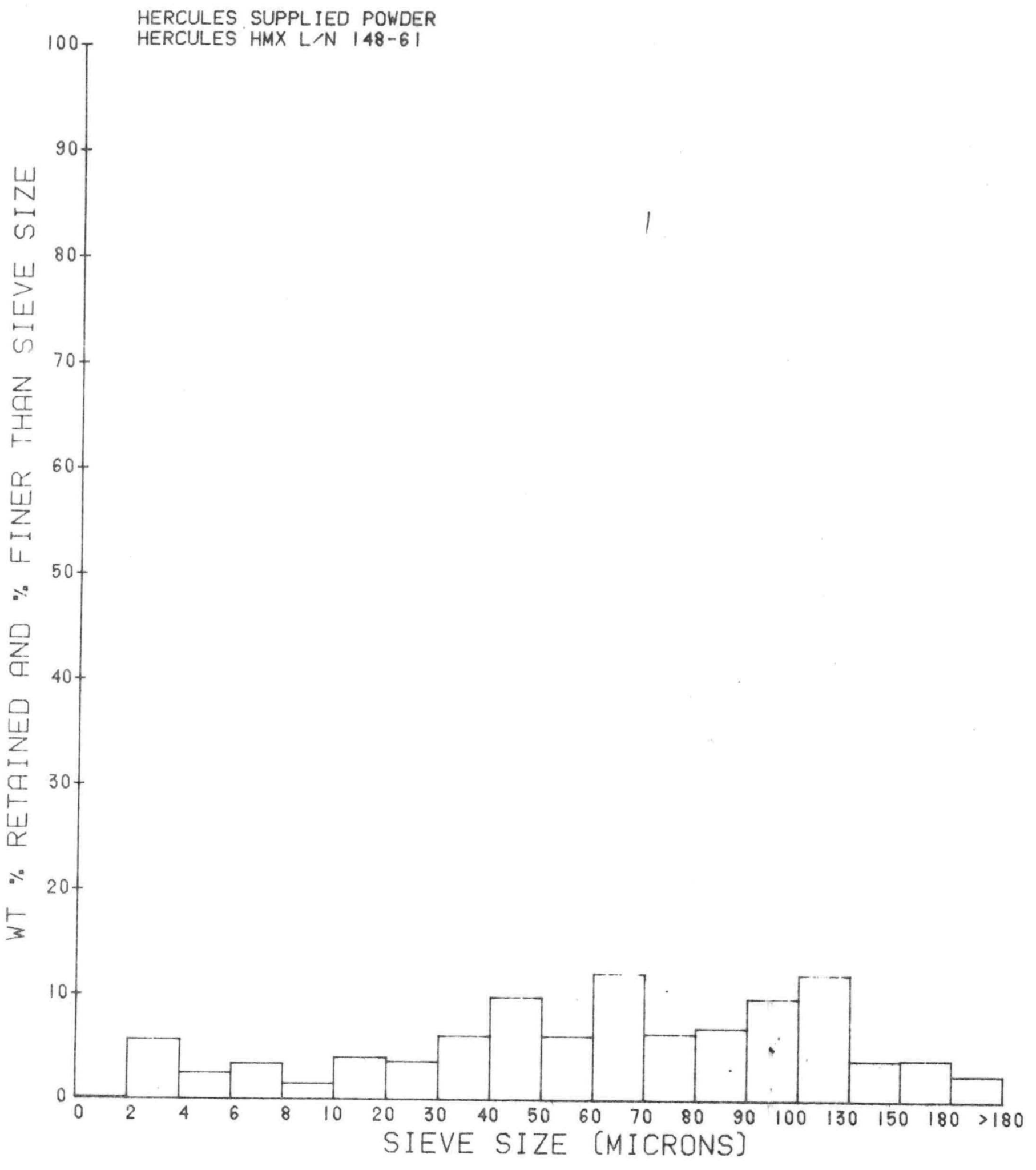




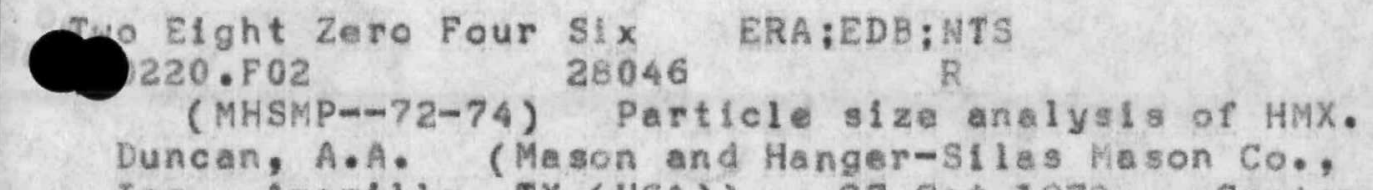

$M N=45 \quad P \quad$ TIC EDE-450100:

FILE- TD0220.FO2

28046 R TD122078 TD122178 ojUncl

orDuncan, A.A.

1. Particle size analysis of HMX

15 MHSMP $--72-74$

24 Contract Ey-76-C-04-0487

3727 Det 1972 3955p. 43 Dep. NTIS, MF A01

4 Fortions of document are $111 \mathrm{eg} 1 \mathrm{bl}$

solther

$51 M N-45 \quad{ }_{2} P$ 53ERA;EDE;NTS

$54 E D B-450100$;

5sTIC 56 United States of America (USA) sqUnited States of Americe

(USA)

$703954000 \quad 72$ Mason and Henger-Silas Mason Co., Inc., Amerillo, TX

(USA)

Cheok DE: 43 AUTHORITY CHECK[DEP.]. 